Full-length Article

\title{
Anti-IL17 treatment ameliorates Down syndrome phenotypes in mice
}

\author{
Noemí Rueda $^{\mathrm{a}}$, Verónica Vidal ${ }^{\mathrm{a}}$, Susana García-Cerro ${ }^{\mathrm{a}}$, Josep Oriol Narcís ${ }^{\mathrm{a}}$, \\ María Llorens-Martín ${ }^{\mathrm{b}, \mathrm{d}, \mathrm{d}}$, Andrea Corrales ${ }^{\mathrm{a}}$, Sara Lantigua ${ }^{\mathrm{a}}$, Marcos Iglesias ${ }^{\mathrm{e}}$, Jesús Merino ${ }^{\mathrm{f}}$, \\ Ramón Merino $^{\mathrm{g}, *}$, Carmen Martínez-Cué ${ }^{\mathrm{a}, *}$ \\ a Department of Physiology and Pharmacology, Faculty of Medicine, University of Cantabria, Santander, Spain \\ b Department of Molecular Neuropathology, Centro de Biología Molecular "Severo Ochoa", CBMSO, CSICUAM, Madrid, Spain \\ ${ }^{\mathrm{c}}$ Network Center for Biomedical Research on Neurodegenerative Diseases (CIBERNED), Madrid, Spain \\ d Department of Molecular Biology, Faculty of Sciences, Universidad Autónoma de Madrid, Madrid, Spain \\ e Department of Plastic and Reconstructive Surgery, Johns Hopkins School of Medicine, Baltimore, USA \\ ${ }^{\mathrm{f}}$ Department of Molecular Biology, Faculty of Medicine, University of Cantabria, Santander, Spain \\ ${ }^{\mathrm{g}}$ Institute of Biomedicine and Biotechnology of Cantabria, Consejo Superior de Investigaciones Cientificas-University of Cantabria, Santander, Spain
}

\section{A R T I C L E I N F O}

\section{Keywords:}

Neuroinflammation

Down syndrome

Ts65Dn

Anti-IL17

\begin{abstract}
A B S T R A C T
Down syndrome (DS) is characterized by structural and functional anomalies that are present prenatally and that lead to intellectual disabilities. Later in life, the cognitive abilities of DS individuals progressively deteriorate due to the development of Alzheimer's disease (AD)-associated neuropathology (i.e., $\beta$-amyloid (A $\beta$ ) plaques, neurofibrillary tangles (NFTs), neurodegeneration, synaptic pathology, neuroinflammation and increased oxidative stress). Increasing evidence has shown that among these pathological processes, neuroinflammation plays a predominant role in $\mathrm{AD}$ etiopathology. In $\mathrm{AD}$ mouse models, increased neuroinflammation appears earlier than $\mathrm{A} \beta$ plaques and NFTs, and in DS and AD models, neuroinflammation exacerbates the levels of soluble and insoluble $\mathrm{A} \beta$ species, favoring neurodegeneration. The Ts65Dn (TS) mouse, the most commonly used murine model of DS, recapitulates many alterations present in both DS and AD individuals, including enhanced neuroinflammation. In this study, we observed an altered neuroinflammatory milieu in the hippocampus of the TS mouse model. Pro-inflammatory mediators that were elevated in the hippocampus of this model included proinflammatory cytokine IL17A, which has a fundamental role in mediating brain damage in neuroinflammatory processes. Here, we analyzed the ability of an anti-IL17A antibody to reduce the neuropathological alterations that are present in TS mice during early neurodevelopmental stages (i.e., hippocampal neurogenesis and hypocellularity) or that are aggravated in later-life stages (i.e., cognitive abilities, cholinergic neuronal loss and increased cellular senescence, APP expression, A $\beta$ peptide expression and neuroinflammation). Administration of anti-IL17 for 5 months, starting at the age of 7 months, partially improved the cognitive abilities of the TS mice, reduced the expression of several pro-inflammatory cytokines and the density of activated microglia and normalized the APP and A $\beta_{1-42}$ levels in the hippocampi of the TS mice. These results suggest that IL17-mediated neuroinflammation is involved in several $\mathrm{AD}$ phenotypes in TS mice and provide a new therapeutic target to reduce these pathological characteristics.
\end{abstract}

\section{Introduction}

Down syndrome (DS), the most common genetic cause of intellectual disability (Shin et al., 2009), is caused by a partial or complete triplication of human chromosome 21 (Hsa21). This intellectual disability is primarily caused by prenatal changes in central nervous system growth and differentiation (Lott, 2012; Haydar and Reeves, 2012). However, later in life, the cognitive abilities of DS individuals progressively decline due to accelerated aging and the development of
Alzheimer's disease (AD)-associated neuropathology. The primary hallmarks of $\mathrm{AD}$, such as the accumulation of amyloid plaques comprising $\beta$-amyloid $(A \beta)$ peptides, neurofibrillary tangles (NFTs) formed by insoluble deposits of abnormally hyperphosphorylated tau, neuroinflammation, synapse and neuronal loss, and regional atrophy, are present in $100 \%$ of individuals with DS by the fourth decade of life (Wilcock and Griffin, 2013; Lott, 2012; Cenini et al., 2012; Sabbagh et al., 2011; Lott and Dierssen, 2010; Teipel and Hampel, 2006).

This high prevalence of AD neuropathology in DS is partially related

\footnotetext{
* Corresponding authors.

E-mail addresses: ramon.merino@unican.es (R. Merino), martinec@unican.es (C. Martínez-Cué).
} 
to the overexpression of several AD-related genes encoded in Hsa21. One of these genes is APP (Amyloid Precursor Protein), and its triplication in DS leads to an increased production of $A \beta$ peptides. An imbalance between $\mathrm{A} \beta$ production and clearance leads to high levels of these peptides, causing their fast aggregation and deposition in plaques. These events induce other AD-associated neuropathologies, such as an increase in oxidative stress, neuroinflammation, and neuronal death and an accelerated decline in learning and memory (Wilcock, 2012; Sipos et al., 2007; Eikelenboom et al., 2006; Hardy, 2006; Weldon et al., 1998; Chong, 1997; Gitter et al., 1995; Hardy and Higgins 1992).

Brain inflammation is one of the most important risk factors for sporadic AD development (Guerreiro et al., 2013). A $\beta$ peptides and APP activate glial cells (Barger and Harmon, 1997; Dickson et al., 1993), leading to cytokine and chemokine production (including Interleukin $1 \beta$ (IL1 $\beta$ ) and Interferon gamma (IFN $\gamma$ )) and, therefore, to increased cytokine and chemokine expression in the AD brain (Meager 2004; 2005; Ho et al., 2005). Cytokines can also induce $A \beta$ generation, tau phosphorylation and oxidative stress (Steele et al., 2007; Blurton-Jones and Laferla, 2006; Sastre et al., 2003). The combination of the activities of some of these cytokines (e.g., IL1 $\beta$ and IFN $\gamma$ ) substantially elevates $A \beta$ secretion and its cellular accumulation (Blasko et al., 2001). Therefore, inflammation can directly influence plaques and NFT formation, and these two neuropathological events can, in turn, increase inflammation.

The neuroinflammatory changes present in the DS brain include microglial and astroglial activation and increased levels of pro-inflammatory cytokines (Wilcock and Griffin, 2013; Griffin, 2006; Park et al., 2005; Griffin et al., 1989). This neuroinflammatory response exacerbates oxidative stress, synaptic dysfunction and neuronal death, and decreases neurogenesis (Lyman et al., 2014; Town et al., 2005; Llorens-Martin et al., 2014; Fuster-Matanzo et al., 2013). Specifically, cytokines affect proliferation, new neuron maturation and neuronal recruitment into relevant circuits (Rosi et al., 2012). Because hippocampal neurogenesis is impaired in DS individuals (see Rueda et al., 2012), neuroinflammation increases their vulnerability to lesions that might contribute to the early onset of dementia (Teipel and Hampel, 2006). Thus, reducing neuroinflammation may be a therapeutic strategy for preventing AD pathology in DS and might also allow endogenous repair mechanisms, such as the formation of new neurons, to partially diminish the functional damage of the hippocampus.

The most commonly used model of DS is the partial trisomic mouse Ts65Dn (TS) (Sturgeon and Gardiner, 2011). TS mice replicate many DS phenotypes, including alterations in behavior, learning and memory, brain morphology and hypocellularity, neurogenesis, neuronal connectivity and electrophysiological and neurochemical processes (Rueda et al., 2012; Bartesaghi et al., 2011). As in DS and AD individuals, the TS mouse shows increased levels of APP, A $\beta$ peptides and oxidative stress in early life stages (Trazzi Fuchs et al., 2013; Tanzi et al., 1987; Busciglio and Yankner, 1995) as well as age-dependent degeneration, including the loss of cholinergic and noradrenergic neurons starting at the age of 6 months (Corrales et al., 2014, 2013; Lockrow et al., 2009; Shichiri et al., 2011). However, TS mice do not show amyloid plaques or NFTs (see Rueda et al., 2012; Rueda et al., 2010; Netzer et al., 2010; Seo and Isacson, 2005; Millan Sanchez et al., 2012). TS mice also exhibit increased neuroinflammation due to microglial activation and to the altered expression of inflammatory cytokines in the brain (Hunter et al., 2004; Lockrow et al., 2011; Roberson et al., 2012). As in DS, the inflammatory events in TS mice can precede, or be simultaneous to, other degenerative processes. Microglial activation may play a significant role in cholinergic degeneration and other pathological hallmarks of $\mathrm{AD}$, and reducing neuroinflammation may provide protection against neurodegeneration. In fact, the administration of minocycline, a synthetic tetracycline with anti-inflammatory properties, ameliorates the cognitive deficits and neurodegenerative phenotypes of TS mice (Hunter et al., 2004).

In the present study, we have observed increased levels of several pro-inflammatory mediators in the hippocampi of 12-month-old TS mice, and we have highlighted the increased levels of IL17A, due to its role in mediating brain damage through its potent pro-inflammatory actions (Meares et al., 2012; Zimmermann et al., 2013; Zimmermann et al., 2018). IL17A is a homodimeric glycoprotein produced by Th17 helper T cells; furthermore, IL17A participates in the development of autoimmunity, inflammation and tumoral immunity and plays a role in the host defense against bacterial and fungal infections (Wu et al., 2015; Murugaiyan et al., 2015; Flores-García and Talamás-Rohana, 2005). The increased production of IL17 is associated with several inflammatory disorders (Beringer et al., 2016; Zimmermann et al., 2018).

Because of its fundamental role in mediating the brain damage of neuroinflammatory processes (Korn et al., 2009; Meares et al., 2012; Zimmermann et al., 2013, 2018), blocking this cytokine has become a promising strategy for anti-inflammatory therapies (Dallenbach et al., 2015; Swardfager et al., 2013; Flores-García and Talamás-Rohana, 2005; Gelderblom et al., 2012). Accordingly, here, we have evaluated the effects of anti-IL17 treatment with an anti-IL17A monoclonal antibody $(\mathrm{mAb})$ on reducing neuroinflammation and on improving cognition, neuromorphological alterations and AD-like neurodegenerative features in the TS mouse model of DS.

\section{Materials and methods}

\subsection{Animals and pharmacological treatments}

Mice were generated by repeated backcrossing of TS females with C57C3HF1 males. To determine the presence of the trisomy, animals were karyotyped using real-time quantitative PCR (qPCR) as previously described (Liu et al., 2003). C3H/HeSnJ mice carry a recessive mutation that leads to retinal degeneration (Rd). Therefore, all animals were genotyped using standard PCR to detect the Rd mutation (Bowes et al., 1993). Experiments were conducted using wt/wt or Rd1/wt animals. Mice were housed under standard laboratory conditions with an inverted dark/light cycle (lights off at 8:00 A.M. and on at 8:00 P.M.). In all experiments, TS mice were compared to euploid littermates (CO).

A total of 72 male mice, aged 7 months at the beginning of treatment, were used and assigned to one of six experimental groups: CO saline $(\mathrm{n}=10)$, TS saline $(\mathrm{n}=10)$, CO anti-IL17 $(\mathrm{n}=13)$, TS anti-IL17 $(n=13)$, CO IgG1-C $(n=13)$ and TS IgG1-C $(n=13)$.

The hybridoma cell line MM17F3, which produced a murine IgG1 anti-mouse IL17A mAb, was a kind gift from Dr. Jacques Van Snick (Ludwig Institute for Cancer Research, Brussels, Belgium). Because polyclonal IgGs may have immunomodulatory activities that are independent of their antigen specificities and because polyclonal IgGs have been used to treat different immunological disorders, such as immunodeficiencies and various inflammatory autoimmune diseases (Zuercher et al., 2016), one group of TS mice and another group of CO mice were treated with a mouse IgG1 anti-TNP isotype control mAb (IgG1-C) and used as vehicle control groups.

From 7 to 11 months of age, the mice in the six groups were injected intraperitoneally with saline or with $0.5 \mathrm{mg}$ /week (in two injections per week) anti-IL17 or IgG1-C.

The behavioral experiments were initiated at 11 months of age and performed for 4 weeks. During this period, the animals received antiIL17, IgG1-C or saline until the end of the behavioral characterization, when they were sacrificed.

In view of the lack of differences between the IgG1-C- and salinetreated groups in the behavioral assessment and cytokine analyses, the neuromorphological, APP and A $\beta$ determinations were carried out only in $\mathrm{CO}$ and TS mice treated with the mAb (vehicle) or anti-IL17.

\subsection{Sacrifice}

After completing the behavioral tests, all animals were perfused with saline. To perform histological analyses the left hemispheres of 7 
animals from the CO IgG1-C, TS IgG1-C, CO anti-IL17 and TS anti-IL17 groups were fixed overnight in $4 \%$ paraformaldehyde, transferred into $30 \%$ sucrose and frozen on dry ice.

To perform the Western blot, ELISA and array experiments, the right hemispheres of the 7 animals used for histological analyses and the whole brains of the animals that were used in the behavioral battery (but not in the histological experiments) were immediately dissected and frozen.

\subsection{Cytokine antibody array}

One-half of the right hippocampus of each of 10 animals from each of the six experimental groups was used to perform a cytokine protein array. Each array was performed on two independent groups of 5 mice from each experimental condition. Samples were homogenized, and protein concentrations were estimated using the BCA Protein Assay Kit (Pierce, Rockford, IL, USA). For each independent group, a pooled protein extract for each experimental condition was prepared in a single tube. The total protein concentration was determined for each mouse to ensure an equal amount of protein corresponding to each animal in the prepared mixture. The mouse cytokine array $\left(\right.$ RayBio $^{\circledR} \mathrm{C}$-series Mouse Cytokine Antibody Array C1000; Ray Biotech Inc., Norcross, GA, USA) consisted of 96 soluble signaling factors and cytokine antibodies spotted in duplicate onto a PVDF membrane. The membranes were blocked with $10 \%$ bovine serum albumin (BSA) in phosphate-buffered saline (PBS) and subsequently incubated with samples overnight at $4{ }^{\circ} \mathrm{C}$. The membranes were washed with buffer supplied by the manufacturer and exposed to 500-fold diluted biotin-conjugated anti-cytokine antibodies at room temperature (RT) for $2 \mathrm{~h}$. The membranes were then washed, incubated with 1000-fold diluted HRP-conjugated streptavidin for $1 \mathrm{~h}$, and immersed for $1 \mathrm{~min}$ in a peroxidase substrate solution. For each spot, the net density of the gray level was normalized by subtracting the background from the total raw density using the Chemidoc XRS system and ImageJ analysis software. For each group of animals, the relative levels of each cytokine were calculated.

\subsection{Behavioral analysis}

\subsubsection{Learning and memory}

To evaluate spatial learning and memory, the platform-relocation protocol of the Morris water maze was used (Saab et al., 2011; Chen et al. 2000; Steele and Morris 1999). This protocol was chosen because the Morris water maze is a more difficult task that provides better discrimination between cognitive performances in different experimental manipulations.

The apparatus consisted of a circular 110-cm-diameter tank filled with water $\left(22-24^{\circ} \mathrm{C}\right)$ that was made opaque by the addition of powdered milk. Inside the tank, a platform was hidden $1 \mathrm{~cm}$ below the water level. Animals were tested in 12 consecutive daily sessions as follows: eight acquisition sessions (platform submerged), followed by four cued sessions (platform visible). All trials were videotaped with a camera located $2 \mathrm{~m}$ above the water level. The Anymaze computerized tracking system (Stoelting, Wood Dale, IL, USA) was used to analyze the mouse trajectories and measure the escape latency for each animal in the trial.

In the acquisition sessions (S1-S8), the platform was hidden $1 \mathrm{~cm}$ below the water level. From one daily session to the next, the platform was placed in a different location (E, SW, center, and NW); each position was used once every four consecutive daily sessions. Each of the eight acquisitions and four cued sessions (one per day) consisted of four pairs of trials that were $30-45 \mathrm{~min}$ apart. For each pair of trials, the mice were randomly started from one of four positions (N, S, E, W), which was held constant for both trials. The first trial of a pair was terminated when the mouse located the platform or when $60 \mathrm{~s}$ had elapsed. The second trial commenced following a period of $20 \mathrm{~s}$, during which the animal was allowed to stay on the platform. Several fixed cues outside of the maze were constantly visible from the pool.

During the cued sessions, the platform was visible, the water level was $1 \mathrm{~cm}$ below the platform, and its position was indicated with a flag. Eight trials were performed during each session using the same experimental procedure as in the acquisition sessions. The mean latency of all trials in all cued sessions is presented.

\subsubsection{Side effects}

2.4.2.1. Motor abilities

2.4.2.1.1. Spontaneous activity. The Acti-system II device (Panlab, Barcelona) was used to measure daily variations in the spontaneous locomotor activity of the animals during a complete $12 / 12 \mathrm{~h}$ light/dark cycle.

2.4.2.1.2. Sensorimotor function and motor coordination. Sensorimotor function was evaluated with a battery of tests, and motor coordination was evaluated with the rotarod test, following the procedures described by Martínez-Cué et al. (2013).

In the visual placing reflex test, cerebellar and vestibular functions were evaluated. In 3 consecutive trials, mice were gently lowered by the tail toward a flat surface from a height of $15 \mathrm{~cm}$. The forepaw-extension response was scored on a $0-4$ scale [4: forepaws extended when placed at the highest level; 3 : forepaws extended before the vibrissae touched the surface; 2: forepaws extended after the vibrissae touched the surface; 1 : forepaws extended after the nose touched the surface; or 0 : no extension].

To evaluate auditory sensitivity, the startle response to a sudden auditory stimulus was measured. Mice were placed facing the wall of an unfamiliar cage, and the auditory stimulus was generated by clapping two stainless steel forceps $(7 \mathrm{~cm}$ long) together. A score $(0-3$ points) was assigned based on the magnitude of the response: jumping more than $1 \mathrm{~cm}$ ( 3 points); jumping less than $1 \mathrm{~cm}$ ( 2 points); retracting the ears (Preyer reflex, 1 point); or no response ( 0 points).

The vibrissa-placing reflex was analyzed by noting the reflexive reaction to touching the vibrissae with a cotton stick. In three consecutive trials, a score of 1 was assigned to animals that touched the stimulated vibrissae with an ipsilateral paw, and a score of 0 was assigned if no response was evident.

Grip strength was assessed by quantifying the resistance to being separated from a lid of aluminum bars $(2 \mathrm{~mm})$, when dragged by the tail (0: no resistance, total loss of grip strength; 1 : slight resistance; 2 : moderate resistance; 3: active resistance; or 4: extremely active resistance, normal grip strength).

To evaluate the equilibrium, four 20-s trials of balance were performed on an elevated (40-cm-high), horizontal (50-cm-long) rod. Trials 1 and 2 were performed on a flat wooden rod ( $9 \mathrm{~mm}$ wide), and trials 3 and 4 were performed on a cylindrical aluminum rod $(1 \mathrm{~cm}$ in diameter). In each trial, the animals were placed in a marked central zone $(10 \mathrm{~cm})$ on the elevated rod. A score of 0 was assigned if the animal fell within $20 \mathrm{~s}, 1$ if the animal stayed within the central zone for $>20 \mathrm{~s}, 2$ if the animal left the central zone, and 3 if the animal reached one of the ends of the bar.

The prehensile reflex (three 5-s trials) was measured as the ability of the animal to remain suspended by the forepaws by grasping an elevated horizontal wire ( $2 \mathrm{~mm}$ in diameter). The maximum possible score of 3 was achieved when the animal remained suspended by the forepaws in all three trials (one point per trial). Traction capacity was scored at simultaneously by assessing the number of hind limbs that the animal raised to reach the wire ( 0 : none; 1 : one limb; or 2: two limbs).

2.4.2.1.3. Motor coordination: rotarod. Motor coordination was evaluated using a rotarod device (Ugo Basile; Comerio, Italy), which consisted of a $37-\mathrm{cm}$-long, 3-cm-in-diameter plastic rod that rotated at different speeds. In a single session, 4 trials with a maximum duration of $60 \mathrm{~s}$ each were performed. In the first three tests, the rod was rotated at constant speeds of 5, 20 and 40 r.p.m., respectively. The last trial consisted of an acceleration cycle, in which the rod rotated progressively faster, and the animal had to adapt to the growing 
demands of the test. The length of time that each animal stayed on the rotarod during the acceleration cycle was recorded.

2.4.2.2. Anxiety. Anxiety and general activity in the open field and plus maze tests were evaluated according to the procedures described by Martínez-Cué et al. (2013).

2.4.2.2.1. Open field. Exploratory behavior and anxiety were assessed using a square-shaped open field $(55 \mathrm{~cm} \times 55 \mathrm{~cm}$, surrounded by a $25-\mathrm{cm}$-tall fence), divided into 25 equal squares. The mice were placed in the center of the field, and the number of vertical (rearing) activities and horizontal crossings (from square to square, subdivided into center vs. peripheral crossings) was scored in a single 5min trial.

2.4.2.2.2. Plus maze. The elevated plus maze consisted of two closed arms $(5 \mathrm{~cm} \times 30 \mathrm{~cm}$, with clear perplex walls that were $15 \mathrm{~cm}$ high) and two open arms ( $5 \mathrm{~cm}$ wide $\times 30 \mathrm{~cm}$ long) that were raised $40 \mathrm{~cm}$ from the floor. In a single 5-min trial, the mice were placed in the center of the maze. The trials were videotaped, and the number of arm entries, the time spent in the open and closed arms and the initial freezing time were measured with the Anymaze computerized tracking system.

\subsection{Histological and stereological procedures}

\subsubsection{Tissue preparation}

The brains were coronally sliced using a cryostat. Fifty- and thirty$\mu \mathrm{m}$-thick sections of the hippocampal and medial septum area, respectively, were collected into culture plates as previously described (Corrales et al., 2014). The series of brain slices containing the hippocampus or medial septum randomly comprised 1 section out of every 9 or 6 slices respectively.

\subsubsection{Nissl staining}

To calculate the total area of the subgranular zone (SGZ) and the dentate gyrus (DG) volume of each mouse, a randomly chosen series was used to perform Nissl staining. Both parameters were measured with the standard Cavalieri method using a semiautomatic system (ImageJ v.1.33, NIH, USA, http://rsb.info.nih.gov/ij/).

\subsubsection{Immunofluorescence}

In order to quantify cell proliferation (Ki67), the density of mature neurons (NeuN), microglial activation (Iba1) and the phenotype of the senescent cells ( $\beta$-galactosidase/NeuN, $\beta$-galactosidase/GFAP and $\beta$ galactosidase/GluR2/3), we performed a series of single or double fluorescence immunohistochemical analyses.

Free-floating slices were initially pre-incubated in phosphate buffer (PB) with $0.5 \%$ Triton $\mathrm{X}-100$ and $0.1 \% \mathrm{BSA}$, and then, slices were incubated with primary antibodies (Table 1) diluted in $\mathrm{PB}$ with $0.5 \%$ Triton X-100 and $0.1 \%$ BSA (PBTBSA) for two days at $4{ }^{\circ} \mathrm{C}$. Then, slices were incubated overnight at $4{ }^{\circ} \mathrm{C}$ with the secondary antibody (Table 1 ). The sections were counterstained with 4'6-diamidino-2-phenylindole (DAPI; Calbiochem, Billerica, MA, USA; $1: 1000$ ) for 10 min in $0.1 \mathrm{M} \mathrm{PB}$ and mounted onto gelatin-covered slides.

\subsubsection{DAB immunohistochemistry of ChAT}

After the inactivation of endogenous peroxidase for $30 \mathrm{~min}$ in $3 \%$ hydrogen peroxide, the free-floating-slices containing the medial septum were washed three times in PBS and blocked for $1 \mathrm{~h}$ in PBS containing $20 \%$ normal donkey serum (NDS) and $0.2 \%$ Triton X-100 prior to overnight incubation at RT with a mixture containing the primary antibody (goat polyclonal Anti-ChAT, Chemicon/Millipore; Billerica, MA, USA; 1:100). After 3 10-min rinses in PBS, the sections were incubated for $2 \mathrm{~h}$ in biotinylated secondary antibody (anti-goat, Vector Laboratories; Peterborough, UK; 1:250) diluted in 2\% NDS/ PBS at RT. The sections were rinsed three times in PBS and incubated for $1 \mathrm{~h}$ at RT in a streptavidin-biotin complex (Vectastain ABC Kit, Vector Laboratories) in PBS for $1 \mathrm{~h}$ at RT. Following a thorough rinse with PBS, immunohistochemical staining was visualized by incubation with 3.3'diaminobenzidine solution (Vector Laboratories). After immunostaining, the sections were mounted on Superfrost plus glass slides, dehydrated, cleared, and coverslipped with mounting medium.

\subsubsection{Cell measurements}

2.5.5.1. Number and density of proliferating cells. The total number of Ki67-positive cells was counted in the SGZ in a series of one-in-nine sections with the help of an optical fluorescence microscope (Zeiss Axioskop 2 plus, $40 \times$ objective) using the previously described optical dissector method (Corrales et al., 2014).

2.5.5.2. Number and density of mature granular cells and neurons in the granule cell layer. Mature granule cells and neurons in the hippocampal granule cell layer (GCL) were counted in a series of one-in-nine sections immunolabeled with NeuN and stained with DAPI. Cell counts were performed using a previously described physical dissector system coupled with confocal microscopy (Llorens-Martin et al., 2006). Random numbers were generated to select the points at which to locate the dissectors. Six dissectors in each section were measured. At the selected points, the confocal microscope (Leica SPE, Leica Microsystems, Wetzlar, Germany) was directed toward a position previously established randomly inside the GCL. Next, at each point, a series of confocal images was serially recorded, keeping to the general rules of the physical dissector and the unbiased stereology. The confocal images were then analyzed on a computer with the aid of ImageJ software (ImageJ, v. 1.33, NIH, Bethesda, MD, USA, http://rsb.info.nih. gov/ij). Every successive pair of images was used, with one considered as the reference image and the other as the sample image. Next, the sample image became the reference image for the following pair of images, and so on. The cells were counted with the NIH ImageJ Cell

Table 1

Antibodies used for immunofluorescence.

\begin{tabular}{|c|c|c|}
\hline ANTIGEN & ANTIBODY - DILUTION - MANUFACTURER & PURPOSE \\
\hline B-galactosidase & $\begin{array}{l}\text { Primary: chicken polyclonal 1:75 (ab134435, Abcam, Cambridge, UK). } \\
\text { Secondary: FITC-conjugated donkey anti-chicken 1:250 (703-095-155, Jackson Immunoresearch, West } \\
\text { Grove, PA, USA). }\end{array}$ & To label senescent cells \\
\hline Glial fibrillary acidic protein (GFAP) & $\begin{array}{l}\text { Primary: rabbit polyclonal 1:1000 (PA3-16727, Thermo Scientific, Rockford, IL, USA). } \\
\text { Secondary: donkey anti-rabbit Alexa Fluor } 594 \text { 1:1000 (A21203, Molecular Probes, Eugene, OR, USA). }\end{array}$ & To label astrocytes \\
\hline Glutamate receptor 2 or $3($ GluR2/3) & $\begin{array}{l}\text { Primary: rabbit 1:100 (AB1506, Millipore, Billerica, MA, USA). } \\
\text { Secondary: donkey anti-rabbit Alexa Fluor } 594 \text { 1:1000 (A21203, Molecular Probes). }\end{array}$ & To label mossy cells \\
\hline Ki67 & $\begin{array}{l}\text { Primary: rabbit monoclonal 1:750 (RM-9106-S, NeoMarkers, Fremont, CA, USA). } \\
\text { Secondary: donkey anti-rabbit Alexa Fluor } 488 \text { 1:1000 (A21206, Molecular Probes). }\end{array}$ & To label proliferating cells \\
\hline Iba1 & $\begin{array}{l}\text { Primary: goat polyclonal 1:500 (ab5076, Abcam). } \\
\text { Secondary: donkey anti-goat Alexa Fluor } 594 \text { 1:1000 (A21203, Molecular Probes). }\end{array}$ & To label activated microglia \\
\hline Neuronal specific nuclear protein (NeuN) & $\begin{array}{l}\text { Primary: rabbit monoclonal 1:3000 (ab177487, Abcam). } \\
\text { Secondary: donkey anti-rabbit Alexa Fluor } 488 \text { 1:1000 (A21206, Molecular Probes). }\end{array}$ & To label neurons \\
\hline
\end{tabular}


Counter, labeling each cell on the screen the first appearance of the cell in the series of confocal images. The software generated the total number of cells when the dissector brick was completed. To count both, namely, the mature granule cells (DAPI ${ }^{+}$) and neurons $\left(\mathrm{NeuN}^{+}\right)$in the GCL, the dissector frame was configured into the shape of a square situated randomly inside the GCL. The number of cells labeled with each marker was then divided by the reference volume of the dissector (this parameter was the volume of a cube formed by the area of the frame multiplied by the height of the dissector) to obtain the number of cells per unit of volume (cell density). The total number of granular cells and mature neurons in the DG was obtained after multiplying the cell density by the volume of DG of each animal.

2.5.5.3. Quantification of area occupied by Iba1 labeling. Microglia were stained with Iba1, and the fluorescence area of Iba1 was quantified. In one series of sections, six independent fields $(175 \times 175 \mu \mathrm{m})$ were randomly selected along the hippocampus and on the neocortex overlaying hippocampus. High-resolution z-stack images (z-step: $0,8 \mu \mathrm{m})$ of Iba1 and DAPI-stained sections were obtained on a confocal microscope (Leica SPE, Leica Microsystems) using a $63 \times$ objective. Z-stacks were opened in ImageJ and converted to maximal projection images with the stack 'max intensity' function. Then, the region occupied by microglial cells and its processes were delimited by applying an automatic local threshold (Otsu). The area occupied by the cells was measured with ImageJ default tools to calculate shape descriptors.

2.5.5.4. Density of cholinergic neurons. The medial septum was photographed using a Zeiss Axioskop 2 plus microscope with a 40X objective, and all ChAT-positive cells were counted with NIH ImageJ Cell Counter software. The number was divided by the volume of the medial septum to calculate the density of this cell population on each animal. The volume of the medial septum in one series of each animal was estimated measuring the area of the medial septum using the ImageJ software and multiplied by the thickness of each section.

\subsection{Senescence: histochemical detection of senescence-associated $\beta$ - galactosidase}

To estimate the density of senescent cells in the SGZ of the dentate gyrus (DG), hippocampal fields CA3 and CA1 and the hilus in the different groups of mice, we used the SA- $\beta$-gal (senescence-associated $\beta$ galactosidase) method described by He et al. (2013). The hippocampal sections were washed twice with PB and fixed for $15 \mathrm{~min}$ at RT with a $0.5 \%$ glutaraldehyde solution. Next, the sections were washed and incubated with a staining solution containing 5-bromo-4chloro-3-indolyl$\beta$-D-galactopyranoside (X-gal, Thermo Fisher Scientific, MA, USA) for $24 \mathrm{~h}$ at $37^{\circ} \mathrm{C}$, mounted on Superfrost plus glass slides, dehydrated, cleared, and coverslipped with mounting medium. The density of SA- $\beta$ gal-positive cells (showing a blue reaction product over the cell soma) in the different hippocampal fields was determined using a Zeiss Axioskop 2 plus microscope. To determine the senescence cell density in the SGZ, the total number of positive cells counted in one series of sections with a $40 \mathrm{X}$ objective was divided by the area of the SGZ (defined as the length of the SGZ divided by the thickness of the section) calculated in the same sections.

The density of SA- $\beta$-gal-positive cells in hippocampal fields CA3 and CA1 and in the hilus was quantified using a systematic random design of dissector counting frames $\left(0.3 \mathrm{~mm}^{2}\right)$. These hippocampal fields were photographed with a $20 \mathrm{X}$ objective. In one series of sections, six independent fields were randomly selected along the CA3 and CA1 hippocampal fields and hilus region. The number of senescent cells was counted within each frame and divided by the area of the dissector to estimate the cellular density. The values were averaged to calculate the density for each animal. Image analysis was performed using NIH ImageJ software.

\subsection{APP protein and A $\beta$-peptides levels}

The levels of APP protein and A $\beta$-peptides were measured in cortical (the whole hemisphere excluding the hippocampus) and hippocampal tissues of TS and CO animals treated with IgG1-C or anti-IL17 (six animals per group) by Western blot and ELISA respectively as previously described by Corrales et al. (2013).

\subsubsection{APP levels: Western blotting}

The cortices and hippocampi from 11 to 12-month-old animals were dissected and stored at $-80{ }^{\circ} \mathrm{C}$ for the immunodetection of APP. Wholecell lysates from the cortex or hippocampus were prepared as previously described (Rueda et al., 2010). The total protein content of each sample was determined using the method described by Lowry et al. (1951). Identical amounts of total protein $(10 \mu \mathrm{g})$ from each sample were loaded on a $10 \%$ sodium dodecyl sulfate-polyacrylamide gel, electrophoresed, and transferred to a polyvinylidene difluoride (PVDF) membrane (Bio-Rad, Hercules, CA, USA) using a Mini Trans-Blot Electrophoresis Transfer Cell (Bio-Rad). The efficient transfer of proteins was confirmed by staining the PVDF membrane with Ponceau red (Sigma-Aldrich, St. Louis, MO, USA). Non-specific binding of antibodies was prevented by incubating the membranes in TBST buffer $(10 \mathrm{mM}$ Tris-HCl, pH 7.6, $150 \mathrm{mM} \mathrm{NaCl}, 0.05 \%$ Tween 20 ) containing $5 \%$ nonfat milk powder. The blots were incubated with the monoclonal mouse primary antibody (raised against an N-terminal epitope of APP; 1:2000, Chemicon/Millipore; Billerica, MA, USA) diluted in TBST containing $2 \%$ non-fat milk powder overnight at $4{ }^{\circ} \mathrm{C}$. After extensive washing with TBST, the blots were incubated with the appropriate peroxidase-labeled secondary antibody (1:40.000, Jackson Labs, West Grove, PA, USA) for $1 \mathrm{~h}$ at RT in the TBST-dry milk buffer.

After the membranes were washed, immunoreactivity was detected with an enhanced chemiluminescence Western blot detection system (ECL Advanced; Amersham-Biosciences, Arlington Heights, IL, USA) and visualized with an Image Quant 350 (GE Healthcare). The integrated optical densities of the bands were then estimated using Scion Image (Scion, Frederick, MD, USA) and normalized to background values. Relative variations between the bands of the TS and CO mice were calculated on the same film. Duplicates of each sample were run on each gel. At least four independent gels were run for each sample. Measurements were within the linear range. To ensure equal protein loading across samples, the blots were reprobed with a mouse monoclonal anti-GAPDH antibody.

\subsubsection{Quantification of $A \beta_{1-40}$ and $A \beta_{1-42}$ in brain tissue}

Sandwich $A \beta$ ELISA was used to measure the hippocampal and cortex levels of $A \beta_{1-40}$ and $A \beta_{1-42}$ in 6 animals from each group. Briefly, the tissue samples were weighed and homogenized in $8 \mathrm{X}$ cold $5 \mathrm{M}$ guanidine hydrochloride buffer $(\mathrm{pH} 8.0)$ and incubated for $3 \mathrm{~h}$ at RT. Samples were diluted with standard dilution buffer (1:10) and centrifuged at $16,000 \mathrm{~g}$ for $20 \mathrm{~min}$ at $4{ }^{\circ} \mathrm{C}$ to remove insoluble material. The supernatant fraction was collected and stored at $-80^{\circ} \mathrm{C}$. To quantify the $A \beta$ levels, the supernatant fractions were analyzed with well-established mouse $A \beta_{1-40}$ and $A \beta_{1-42}$ ELISA kits (KMB 3481 and KMB 3441, respectively; Invitrogen, Carlsbad, CA, USA), following the manufacturer's instructions. Analyses were always performed in duplicate. OD450 values were measured on a microplate reader (Multiskan EX, Thermo Electron Corporation). The $A \beta_{1-40}$ and $A \beta_{1-42}$ levels were calculated according to a standard curve.

\subsection{Statistical analysis}

The water maze data of the acquisition sessions (sessions 1-8) were analyzed using two-way ANOVA with repeated measures (RM) ('session' $\mathrm{x}$ 'genotype' $\mathrm{x}$ 'treatment' or 'trial' $\mathrm{x}$ 'genotype' $\mathrm{x}$ 'treatment'). The rest of the data were analyzed using two-way ('genotype' $x$ 'treatment') ANOVA. The mean values of each experimental group were compared 
post hoc with Student's t-tests if two groups were compared or with Bonferroni tests if more than two groups were compared. All analyses were performed using SPSS for Windows version 22.0.

\section{Results}

\subsection{Inflammatory microenvironment in the hippocampus of TS mice: effect of anti-IL17 treatment}

Because increased neuroinflammation is implicated in AD neuropathology and in the characteristic neurodegeneration of DS and TS mice (Wilcock and Griffin, 2013; Hunter et al., 2004; Roberson et al., 2012; Mulet et al., 2017), we first explored the expression pattern of a large panel of soluble immune mediators in the hippocampi of TS mice and $\mathrm{CO}$ mice.

Of a panel of 96 immune mediators, only eight were significantly modified in the TS animals. Fig. 1 shows the expression levels of the cytokines and chemokines that were altered in these mice, while Table 2 presents the results of the multivariate analysis of each immune mediator selected.

The levels of the pro-inflammatory mediators IL17A, IFN- $\gamma$, IL1 $\beta$, IL15, IL3, macrophage inflammatory protein-3 (MIP3 $\alpha$ ), and

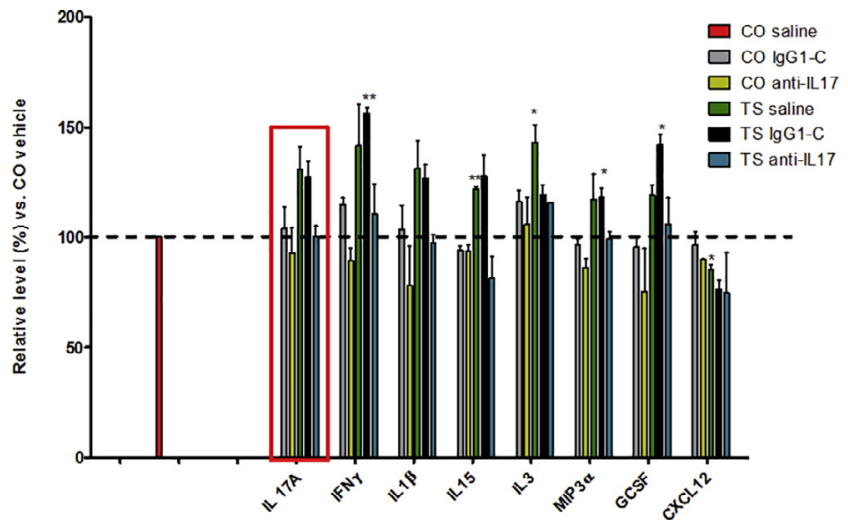

Fig. 1. Hippocampal inflammatory milieu of the different groups of mice treated with saline, IgG1-C or anti-IL17. Mouse cytokine protein arrays were performed on two identical independent groups comprising 5 mice from each experimental group. The figure shows only the pro-inflammatory mediators with statistically significant differences between the experimental conditions. The values correspond to the \% change with respect to the vehicle control group. * $: \mathrm{p}<0.05{ }^{* * *}: \mathrm{p}<0.01$, TS vs. CO; Bonferroni tests after significance by ANOVA.

Table 2

MANOVA $p$ values (genotype $\mathrm{x}$ treatment) for inflammatory mediators in the hippocampus of the six animal groups.

\begin{tabular}{|c|c|c|c|c|c|}
\hline \multirow{3}{*}{$\begin{array}{l}\text { Inflammatory } \\
\text { Mediator }\end{array}$} & \multirow{3}{*}{$\begin{array}{l}\text { MANOVA } \\
\text { GENOTYPE; } \\
\mathrm{F}_{(1,6)}\end{array}$} & \multicolumn{4}{|c|}{ MANOVA TREATMENT } \\
\hline & & \multicolumn{2}{|c|}{ IgG1-C; F $(1,4)$} & \multicolumn{2}{|c|}{ Anti-IL17; F $(1,4)$} \\
\hline & & Treatment & $\begin{array}{l}\text { Genotype } \\
\mathrm{x} \\
\text { treatment }\end{array}$ & Treatment & $\begin{array}{l}\text { Genotype } \\
\mathrm{x} \\
\text { treatment }\end{array}$ \\
\hline IL17A & $\mathrm{p}=\mathbf{0 . 0 2 6}$ & $\mathrm{p}=0.98$ & $\mathrm{p}=0.65$ & $\mathrm{p}=\mathbf{0 . 0 1 7}$ & $\mathrm{p}=0.15$ \\
\hline $\mathrm{IFN} \gamma$ & $p=0.047$ & $\mathrm{p}=0.36$ & $\mathrm{p}=0.99$ & $\mathrm{p}=\mathbf{0 . 0 3 3}$ & $\mathrm{p}=0.39$ \\
\hline MIP3A & $\mathrm{p}=0.036$ & $\mathrm{p}=085$ & $\mathrm{p}=0.73$ & $\mathrm{p}=0.007$ & $\mathrm{p}=0.46$ \\
\hline IL-1 $\beta$ & $\mathrm{p}=0.04$ & $\mathrm{p}=0.95$ & $\mathrm{p}=0.67$ & $\mathrm{p}=0.039$ & $\mathrm{p}=0.74$ \\
\hline IL-3 & $\mathrm{p}=0.012$ & $\mathrm{p}=0.50$ & $\mathrm{p}=0.02$ & $\mathrm{p}=0.57$ & $p=0.66$ \\
\hline IL-15 & $\mathrm{p}=0.004$ & $\mathrm{p}=0.98$ & $\mathrm{p}=0.28$ & $\mathrm{p}=0.001$ & $\mathrm{p}=0.003$ \\
\hline G-CSF & $\mathrm{p}=0.002$ & $\mathrm{p}=0.91$ & $\mathrm{p}=0.068$ & $\mathrm{p}=0.023$ & $\mathrm{p}=0.72$ \\
\hline CXCL12 & $\mathrm{p}=0.012$ & $\mathrm{p}=0.19$ & $\mathrm{p}=0.53$ & $\mathrm{p}=0.29$ & $\mathrm{p}=0.86$ \\
\hline
\end{tabular}

granulocyte colony-stimulating factor (G-CSF) were significantly higher in the hippocampi of the TS mice than in the hippocampi of the $\mathrm{CO}$ animals. In addition, the expression of the chemokine CXCL12 was reduced in the hippocampi of the TS compared to the hippocampi of the CO mice.

The hippocampal expression of these pro-inflammatory mediators was not modified by the chronic treatment of the TS or CO mice with IgG1-C compared to the saline-treated TS or CO mice (Table 2).

To explore whether the increased expression of IL17A observed in the hippocampi of the TS mice was involved in the inflammatory milieu observed in the hippocampi of these animals, we determined whether chronic inhibition of this cytokine with the anti-IL17 mAb normalized the levels of the cytokines and chemokines that were altered. The administration of anti-IL17 mAb, but not of IgG1-C, caused a notable reduction in the hippocampal expression levels of the pro-inflammatory mediators IL17A, IFN $\gamma$, IL1 $\beta$, IL15, MIP3 $\alpha$ and G-CSF in the TS mice (Fig. 1, Table 2). In fact, the anti-IL17 treatment normalized the levels of these inflammatory mediators in the TS mice, evidenced by levels that were equivalent to those of the IgG1-C- or saline-treated $\mathrm{CO}$ mice. However, post hoc comparison showed that anti-IL17 did not modify the levels of these inflammatory mediators in the hippocampi of the $\mathrm{CO}$ mice (IL17A: $p=0.65 ;$ IFN- $\gamma: p=0.31 ;$ IL1 $\beta: p=0.55$; IL15: $p=0.28$; IL3: $p=0.90 ;$ MIP3 $\alpha: p=0.085$; G-CSF: $p=0.33$; and CXCL12: $\mathrm{p}=0.07$ )

In addition, we analyzed the levels of activated microglia in the hippocampus and in the neocortex overlapping hippocampus in the four groups of mice using immunofluorescence for Iba1. Iba1 immunoreactivity was increased in the hippocampi of TS mice ( $\mathrm{p}=0.039$, Fig. 2). In the cortices of these animals, a tendency to present enhanced activated microglia was also found, although this effect did not reach statistical significance ( $\mathrm{p}=0.19$, Fig. 2B). Chronic administration of anti-IL17 reduced the levels of activated microglia in the cortex of TS mice $(\mathrm{p}=0.02)$. This treatment also produced a tendency toward a reduction in the levels of activated microglia in the hippocampi of TS mice that did not reach statistical significance $(p=0.097)$. However, after anti-IL17 treatment, the levels of activated microglia in trisomic mice did not differ from those in IgG1-C-treated CO animals $(\mathrm{p}=0.23$, Fig. 2B).

3.2. Anti-IL17 administration improved the cognitive performances of the TS and CO mice in the Morris water maze without affecting their motor or motivational abilities

The difficulties in escaping from the water maze were greater for the TS animals under all treatments than for the CO mice $(\mathrm{p}<0.001$; Fig. 3A). Anti-IL17 administration improved the learning abilities of both the TS and $\mathrm{CO}$ animals, as demonstrated by their reduced latencies in escaping from the water maze compared with those of the IgG1-Ctreated animals of the same genotype ( $\mathrm{p}=0.008$; Fig. $3 \mathrm{C})$. In addition, the performances of the TS and CO mice that received IgG1-C did not differ from those that received saline (Fig. 3B). Therefore, the treatment with the isotype control IgG1-C did not alter cognition in the animals.

When the learning curves of each pair of groups (differing in phenotype or treatment) were analyzed post hoc, a large difference was found between the performance of the IgG1-C-treated TS and that of the CO mice ( $\mathrm{p}<0.001)$. However, the anti-IL17 treatment reduced these differences since the difference between the learning curves of the IgG1-C-treated CO animals and anti-IL17-treated TS animals was no longer significant (Fig. 3C).

Next, the strategy used by the animals to search for the platform, namely, procedural learning, was analyzed. The TS animals spent more time swimming in the periphery of the maze than the $\mathrm{CO}$ animals ( $<<0.001$; Fig. 3D). However, the time spent by the IgG1-C-treated TS and CO mice in the periphery did not differ from the time spent by the saline-treated mice of the same genotype (Fig. 3E), and the antiIL17 treatment slightly reduced the thigmotactic behavior of the mice, 


\section{A}

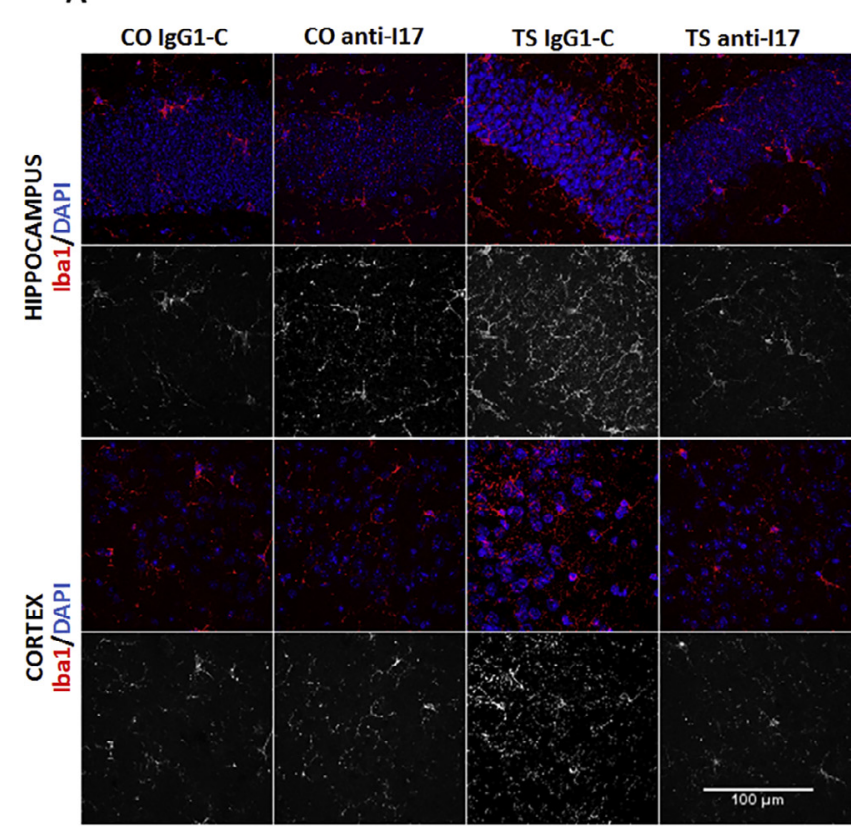

B

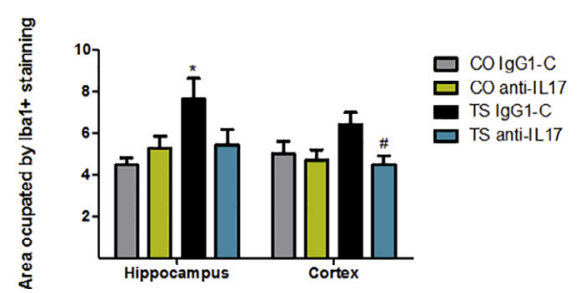

Fig. 2. Representative images of Iba1 and DAPI staining in the hippocampus (first and second row) and cortex (third and fourth row) of TS and CO mice treated with anti-IL17 or vehicle (A). Mean \pm S.E.M. of the area occupied by Iba1 + staining in the hippocampus and cortex of the four groups of mice (B). *: $\mathrm{p}<0.05$ TS vs. CO; ${ }^{*}: \mathrm{p}<0.05$ anti-IL17 vs. vehicle. Bonferroni tests after significant ANOVAs.

although this effect was not statistically significant ( $p=0.057$; Fig. 3F).

During the cued trials the six groups of animals did not differ significantly in their latency to reach the platform when it was visible (Fig. 3G). In addition, no significant differences were found in the swimming speeds of the six groups of animals during the acquisition or cued trials (data not shown). Therefore, the differences in performance found between the groups of mice during the acquisition sessions were unlikely to be due to changes in their motor or motivational abilities.

\subsection{Anti-IL17 treatment ameliorated the deficits in cell proliferation and} survival in the TS mice, without affecting their CO littermates

The vehicle-treated TS group (TS IgG1-C) showed impaired proliferation in the SGZ of the DG, as demonstrated by a reduced density ( $p=0.012$; Fig. 4B) and total number $(p=0.007$; Fig. 4C) of Ki67 + cells in this area. Anti-IL17 treatment increased cell proliferation in TS mice, since the total number of Ki67 + cells was higher in these animals than in mice of the same genotype that received vehicle ( $p=0.044$, Fig. 4C). When the density of this population of cells was compared in both groups of animals, a non-significant tendency to present higher proliferation was found in the anti-IL17-treated TS group ( $p=0.084$; Fig. 4B). Cell proliferation was not affected by treatment in CO mice.

When the number of DAPI + cells was analyzed, the TS group showed a reduction in the density ( $p<0.001$; Fig. 5A, 5B and $5 \mathrm{C}$ ) and total number ( $p=0.05$; Fig. $5 \mathrm{D})$ of these cells. After chronic treatment with anti-IL17, the TS group showed less marked hypocellularity, as demonstrated by the slight increase in the density and total number of DAPI + cells (Fig. 5C and 5D), although this effect was not statistically significant.

Because most DAPI + cells in the granule layer of the DG are mature neurons, we analyzed the impact of anti-IL17 treatment in this population of cells. TS mice presented a reduced density ( $p=0.022$, Fig. $5 B$ and 5E) and total number ( $\mathrm{p}=0.035$, Fig. 5B and 5F) of NeuN + cells. Similar to what was found with the number of DAPI + cells, chronic treatment with anti-IL17 did not exert a significant effect on the number or density of mature neurons. However, anti-IL17 treatment slightly increased both parameters, and the differences between TS mice receiving this antibody and vehicle-treated $\mathrm{CO}$ mice were no longer significant (total number: $\mathrm{p}=0.34$; density: $\mathrm{p}=0.17$, Fig. $5 \mathrm{E}$ and $5 \mathrm{~F}$ ).

\subsection{The cholinergic neurodegeneration and enhanced cellular senescence found in TS animals was ameliorated after anti-IL17 administration}

The vehicle-treated TS group (TS IgG1-C) showed a decreased density of cholinergic neurons in the basal forebrain compared to the CO group ( $\mathrm{p}=0.027$; Fig. 6). However, after treatment with anti-IL17, the density of ChAT + cells became higher in the TS group than in the vehicle-treated group of the same genotype, but this effect was not statistically significant. Anti-IL17 administration did not modify the density of ChAT + cells in the CO mice.

The IgG1-C-treated TS group also displayed a larger population of cells with a senescent phenotype in the SGZ, CA1 and hilus hippocampal areas ( $p<0.01$; Fig. 7 ) than the CO group. These animals also presented an increase in the density of this population of cells in CA3 although this effect did not reach statistical significance. Anti-IL17 treatment induced a reduction in the density of senescent cells in all areas analyzed in the TS group compared with the vehicle-treated TS group, although this effect only reached statistical significance in the hilus ( $p<0.001$; Fig. 7C). However, anti-IL17-treated mice did not differ from vehicle-treated $\mathrm{CO}$ mice in terms of the density of senescent cells present in any of the hippocampal areas assessed.

Anti-IL17 administration did not modify the density of or senescent cells in the $\mathrm{CO}$ mice.

To analyze the phenotype of the senescent cells in the hilar region, we performed three double immunohistochemical experiments. Fig. 8A shows a high incidence of co-localization of $\beta$-galactosidase and NeuN staining, indicating that a high proportion of senescent cells were neurons. Mossy cells comprise the predominant hilar cell population and are immunoreactive for glutamate receptor type 2 or 3 (GluR2/3). In this study, the vast majority of these neurons were mossy cells as they were immunopositive for both $\beta$-galactosidase and GluR2/3 (Fig. 8C). However, glial cells did not appear to be affected by senescence since the co-occurrence of $\beta$-galactosidase and GFAP staining was almost totally absent (Fig. 8B).

3.5. Anti-IL17 administration normalized the protein expression levels of $A P P$ and the $A \beta_{1-42}$ peptide in the hippocampi, but not in the cortices, of TS mice

The TS group showed enhanced protein levels of APP in the cortex ( $p<0.001$ ) and hippocampus ( $p=0.001$; Fig. 9A). These levels were reduced by the anti-IL17 treatment in the hippocampi of the TS animals ( $\mathrm{p}=0.003$ ) but not in the cortices.

In addition, the TS animals showed enhanced expression of $A \beta_{1-42}$ in the hippocampi $(\mathrm{p}=0.023$; Fig. $9 \mathrm{~B})$ that was completely rescued after the administration of anti-IL17. This treatment also reduced the levels of $A \beta_{1-42}$ in the $C O$ animals $(p=0.001)$. However, the amount of $A \beta_{1-42}$ found in the cortices did not differ significantly between the four groups of mice (Fig. 9B).

The TS mice also showed increased levels of $A \beta_{1-40}$ in the 

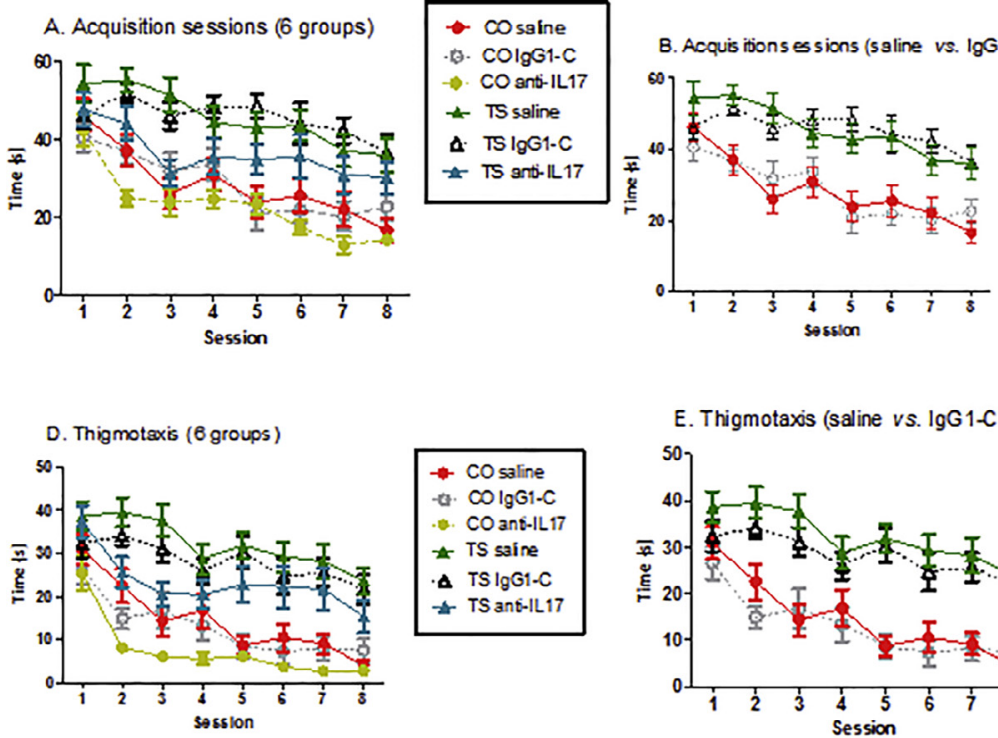

E. Thigmotaxis (saline vs. lgG1-C)

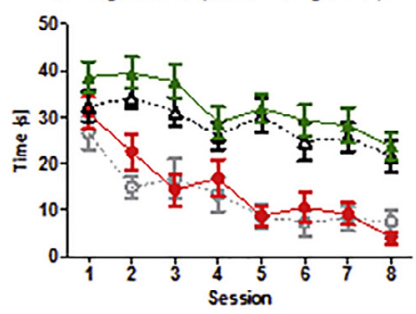

G. Cued sessions

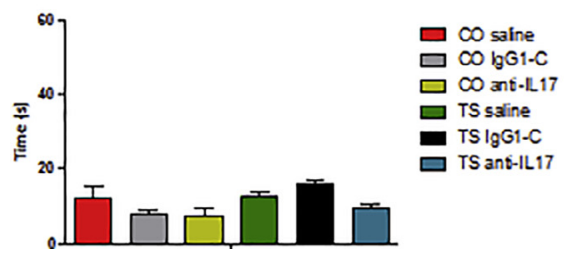

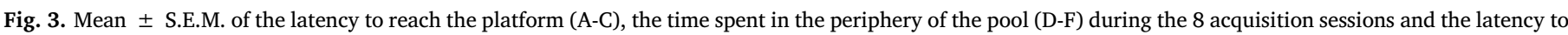

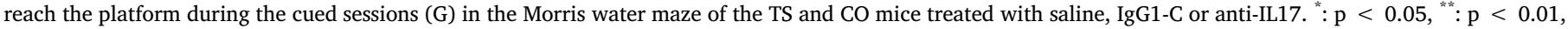
${ }^{* * * *}: \mathrm{p}<0.001$, TS vs. CO; ${ }^{\#}: \mathrm{p}<0.05,{ }^{\# \#}: \mathrm{p}<0.01$, IgG1-C vs. anti-IL17; Bonferroni tests after significance by ANOVA.

A

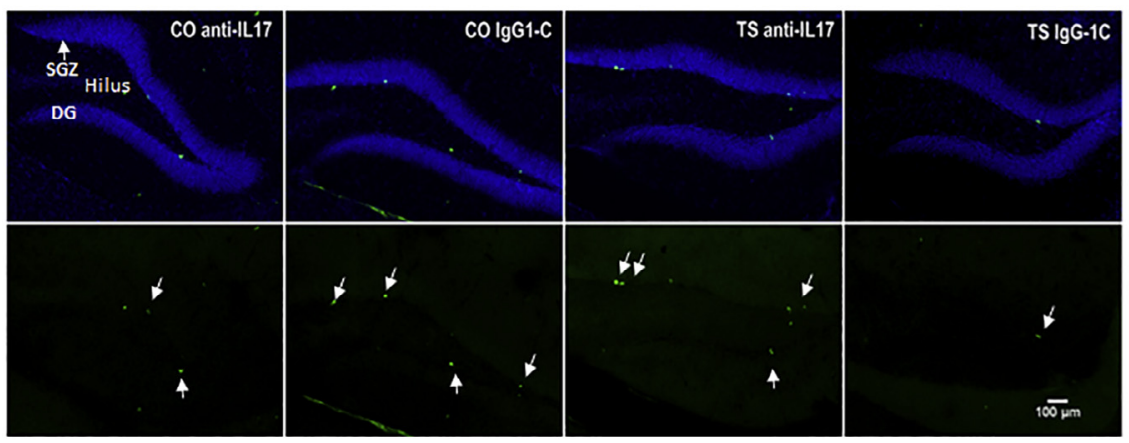

B
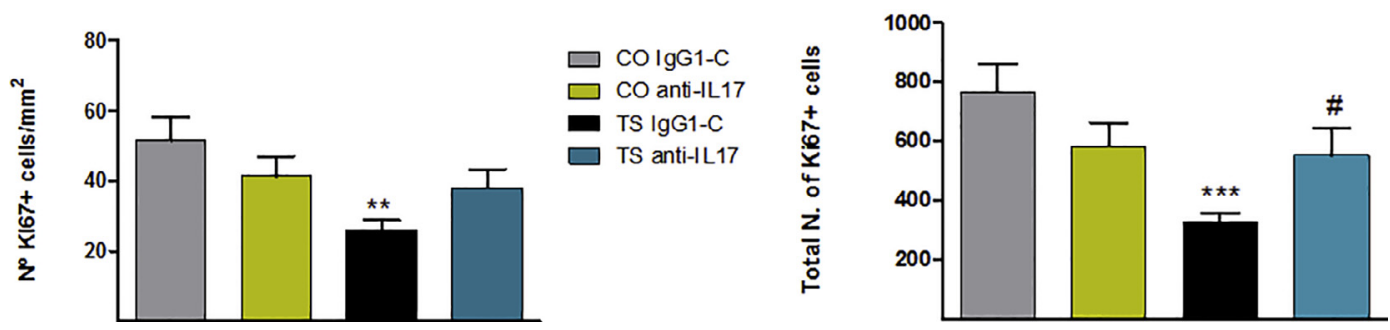

Fig. 4. Representative images of Ki67 + cells (green) in the hippocampi of the TS and CO mice (A) and the mean \pm S.E.M. of the density (B) and total number (C) of Ki67 + cells in the subgranular zone of the hippocampi of the TS and CO IgG1-C- and anti-IL17-treated mice. ${ }^{* * *}: \mathrm{p}<0.01,{ }^{* * * *}: \mathrm{p}<0.001$, TS vs. CO; ${ }^{\#}: \mathrm{p}<0.05$ anti-IL17 vs. vehicle. Bonferroni tests after significance by ANOVA. SGZ: Subgranular Zone. DG: Dentate Gyrus. (For interpretation of the references to colour in this figure legend, the reader is referred to the web version of this article.) 


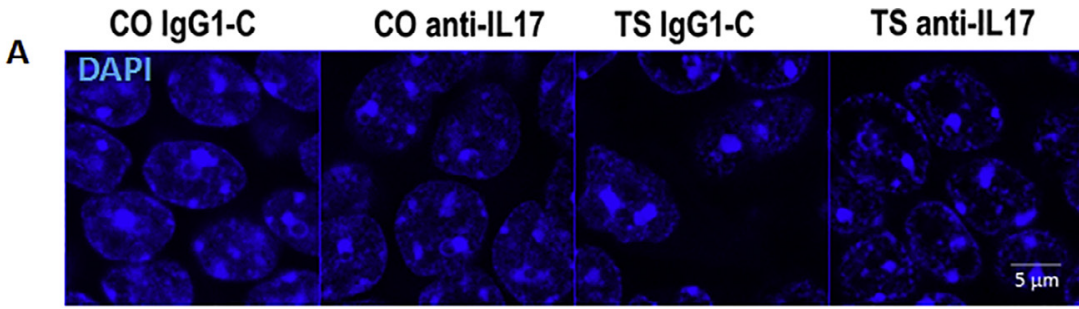

B
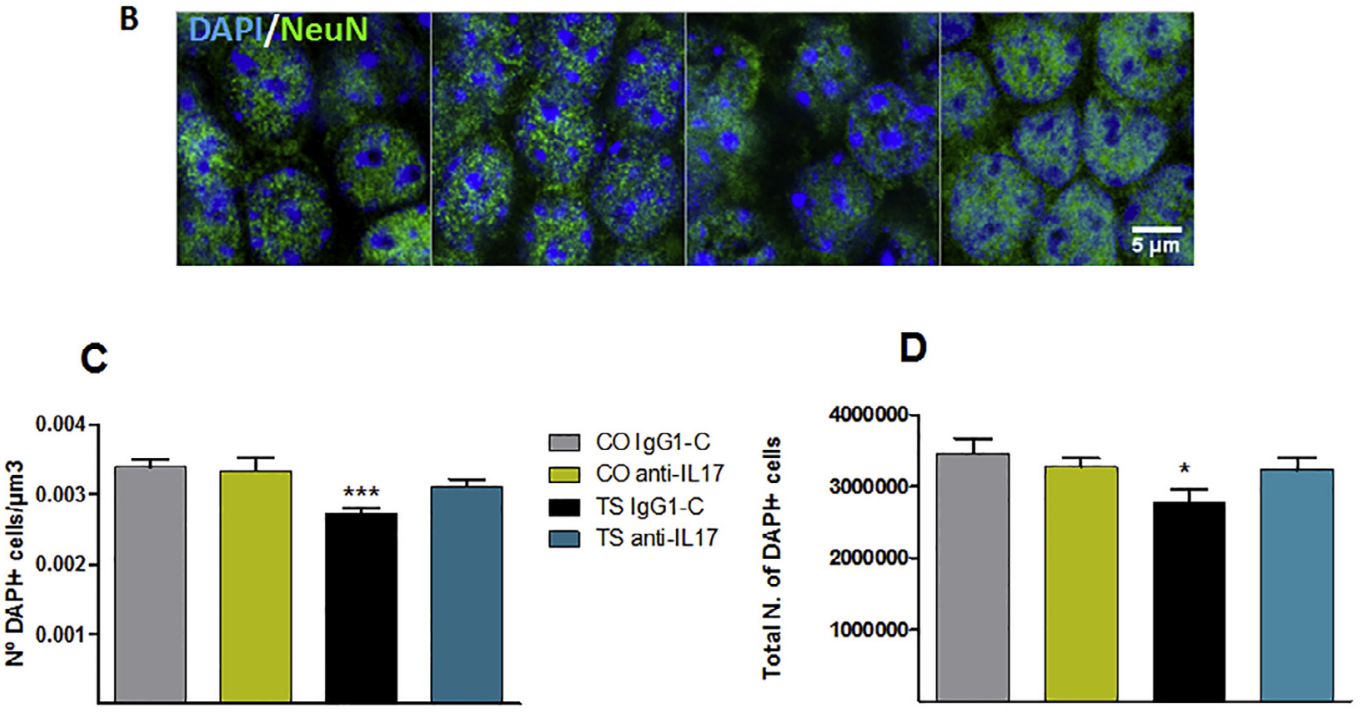

E
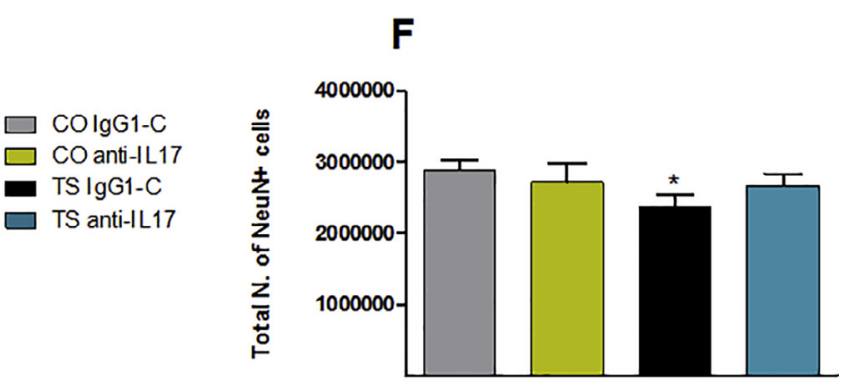

Fig. 5. Representative images of DAPI + cells (A) and DAPI and NeuN + cells (B) in the dentate gyrus of the TS and CO IgG1-C- and anti-IL17-treated mice. Mean \pm S.E.M. of the density (C) and total number (D) of DAPI + cells and the density (E) and total number (F) of NeuN + cells in the DGs of the four groups of mice. ${ }^{*}: \mathrm{p}<0.05,{ }^{* * *}: \mathrm{p}<0.001$, TS vs. CO; Bonferroni tests after significance by ANOVA.

hippocampi ( $\mathrm{p}=0.004$; Fig. 9C) and cortices $(\mathrm{p}=0.001)$. However, chronic administration of anti-IL17 did not reduce the levels of this peptide in the TS or CO mice in either the hippocampus or the cortex.

3.6. Side effects: chronic treatment with anti-IL17 did not affect the sensorimotor abilities, spontaneous activity, motor coordination or anxiety levels of the TS or CO mice

In the different behavioral tests performed to assess the putative side effects of anti-IL17, the IgG1-C- and saline-treated animals achieved similar scores. Because IgG1-C administration did not modify the behaviors of the animals in any test (data not shown), we have only presented the performance data of the IgG1-C-treated mice and antiIL17-treated mice.

In the sensorimotor test battery, the aged TS mice demonstrated impaired equilibrium and motor coordination (latency to fall and number of crossings) in the coat hanger test. However, chronic anti-IL17 administration did not affect equilibrium or the different reflexes of the motor abilities of the TS or CO mice (Table 3).

In addition, the different groups of mice did not differ in the spontaneous activity performed in their home cage during a complete 24hour cycle (dark hours: 'genotype', $\mathrm{p}=0.22$; 'treatment', $\mathrm{p}=0.38$; and 'genotype $\mathrm{x}$ treatment', $\mathrm{p}=0.96$; light hours: 'genotype', $\mathrm{p}=0.61$; 'treatment', $\mathrm{p}=0.19$; and 'genotype $\mathrm{x}$ treatment', $\mathrm{p}=0.54$; Fig. 10A).

Motor coordination in the Rotarod was not affected by the genotype or treatment, as demonstrated by the similar latencies in falling from this apparatus that were displayed by the four groups of mice during the different constant speeds (20 r.p.m.: 'genotype', $\mathrm{p}=0.60$; 'treatment', $\mathrm{F}_{(1,48)}=1.11, \mathrm{p}=0.29$; and 'genotype $\mathrm{x}$ treatment', $\mathrm{p}=0.71 ; 40$ r.p.m.: 'genotype', $\mathrm{p}=0.15$; 'treatment', $\mathrm{p}=0.55$; and 'genotype $\mathrm{x}$ treatment', $\mathrm{p}=0.71$; Fig. 10B) or during the acceleration cycle ('genotype', $\mathrm{p}=0.35$; 'treatment', $\mathrm{p}=0.59$; and 'genotype $\mathrm{x}$ treatment', $\mathrm{p}=0.77$; Fig. 10C).

Anti-IL17 treatment did not affect locomotor activity or anxiety in the TS or CO mice. In the open field test, there were no significant differences in the total distances traveled by the four groups of mice ('genotype', $\mathrm{p}=0.095$; 'treatment', $\mathrm{p}=0.91$; and 'genotype $\mathrm{x}$ treatment', $\mathrm{p}=0.60$; Fig. 11A). The apparent anxiety levels were not different between the TS and CO mice under both treatments since these mice traveled similar distances in the center (ANOVA: 'genotype', $\mathrm{p}=0.08$; 'treatment', $\mathrm{p}=0.63$; and 'genotype $\mathrm{x}$ treatment', $\mathrm{p}=0.40$ ) and periphery of the maze ('genotype', $\mathrm{p}=0.15$; 'treatment', $\mathrm{p}=0.96$; and 'genotype $\mathrm{x}$ treatment', $\mathrm{p}=0.75$; Fig. 11A). The four groups of mice also displayed similar amounts of vertical activity, namely, attempts to 
A

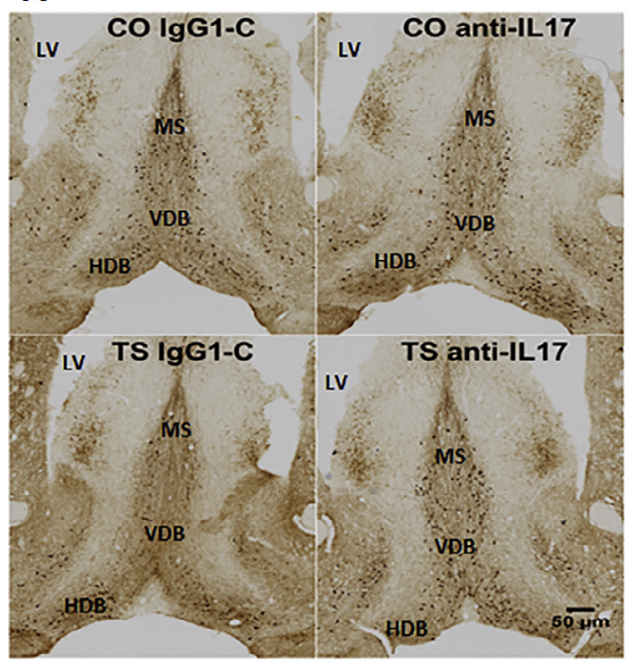

B

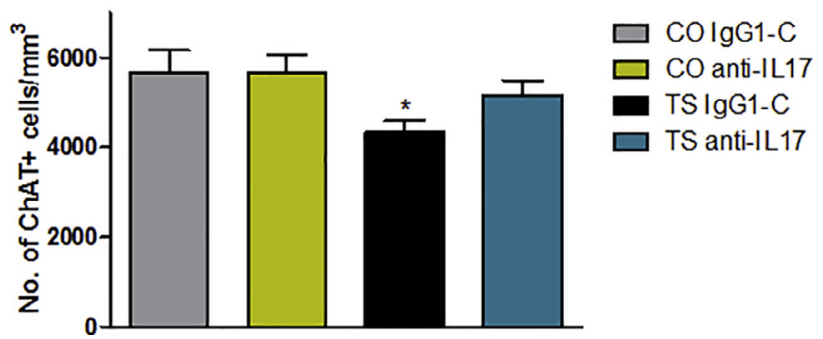

Fig. 6. Representative images of ChAT immunostaining in the septum (A) and the mean \pm S.E.M. of the density of ChAT + cells (B) in the medial septum of the IgG1-C- and anti-IL17-treated CO and TS mice. " $\mathrm{p} p<0.05$, TS vs. CO; Bonferroni tests after significance by ANOVA. LV: lateral ventricle. MS: Medial septal nucleus. VDB: Nucleus of the vertical limb of the diagonal band. HDB: Nucleus of the horizontal limb of the diagonal band.

escape from the maze ('genotype', $\mathrm{p}=0.62$; 'treatment', $\mathrm{p}=0.48$; and 'genotype $\mathrm{x}$ treatment', $\mathrm{p}=0.56$; Fig. 11B).

Finally, in the plus maze test, the anxiety displayed by the animals was not modified by the administration of anti-IL17. The TS and CO mice treated with the vehicle or antibody performed similar numbers of entries into the open arms ('genotype', $\mathrm{p}=0.20$; 'treatment', $\mathrm{p}=0.53$; 'genotype $\mathrm{x}$ treatment', $\mathrm{p}=0.19$ ), performed similar total numbers of entries ('genotype', $\mathrm{p}=0.55$; 'treatment', $\mathrm{p}=0.65$; and 'genotype $\mathrm{x}$ treatment', $\mathrm{p}=0.37$; Fig. 12A), had similar durations of initial freezing times ('genotype', $\mathrm{p}=0.18$; 'treatment', $\mathrm{p}=0.74$; and 'genotype $\mathrm{x}$ treatment', $\mathrm{p}=0.50$; Fig. 12B) and had similar percentages of time spent in the open arms ('genotype', $\mathrm{p}=0.10$; 'treatment', $\mathrm{p}=0.23$; and 'genotype $x$ treatment', $p=0.52$; Fig. $12 \mathrm{C}$ ). These results indicated that the anxiety displayed by the animals was not affected by the genotypes of the animals or the treatment received.

\section{Discussion}

Neuroinflammation contributes to the progression of cognitive decline in patients with $\mathrm{AD}$ and DS. In DS, neuroinflammation is an early event that precipitates and aggravates $\mathrm{AD}$ neuropathology and cognitive decline (Wilcock and Griffin, 2013; Wenk et al., 2000; Griffin et al., 1989). Accordingly, in this study, we observed increased levels of activated microglia and of the expression of several pro-inflammatory mediators in the hippocampi of 12-month-old TS mice. Among these mediators, we focused our attention on IL17 due to its role in mediating brain damage through its potent pro-inflammatory actions (Meares et al., 2012; Zimmermann et al., 2013). Here, using an anti-IL17 mAb that crosses the blood brain barrier (St-Amour et al., 2013), we report that in the TS mouse model of DS, the chronic inhibition of this cytokine reduced neuroinflammation, ameliorated cognitive and neuromorphological alterations and alleviated AD-like neurodegenerative features, such as cholinergic neurodegeneration and cellular senescence in different areas of the hippocampus. In addition, the anti-IL17 treatment reduced alterations found from early developmental stages or early life stages, such as the deficits in hippocampal cell proliferation and neuronal survival and increases in hippocampal APP and $A \beta_{1-42}$ peptide levels, in the TS mice.

The altered expression of pro-inflammatory cytokines and chemokines plays an important role in the appearance of $\mathrm{AD}$ neuropathological changes associated with the progression of cognitive decline in DS (Carta et al., 2002). We have demonstrated that TS mice present an altered hippocampal inflammatory milieu characterized by increased levels of pro-inflammatory mediators IL17A, IL1 $\beta$, IFN $\gamma$, G-CSF, MIP3 $\alpha$, IL3 and IL15, which may play important roles in the progression of AD neuropathology and cognitive decline of aged TS mice. Few studies have evaluated cytokine and chemokine alterations in the brains of DS mouse models, and these studies have reported controversial results. Although increased levels of IL1 $\beta$ have been reported in the hippocampi (Lockrow et al., 2011) and plasma of TS mice (Hamlett et al., 2018), Roberson et al. (2012) found that the expression levels of this pro-inflammatory cytokine were reduced in these animals. Furthermore, some of the cytokines and chemokines that we found to be increased in the TS hippocampi of the present study were either unchanged (IL15 or IFN $\gamma$ ) or undetectable (G-CSF and IL17) in the Roberson et al. (2012) study. However, consistent with our results, Wenk et al. (2000) observed increased levels of IFN $\gamma$ in the whole-brain homogenates of a Ts16 model of DS. In addition, in the present study, we did not find significant changes in the levels of CD40, granulocyte-macrophage colony-stimulating factor (GM-CSF), IL6, IL10, macrophage inflammatory protein $(\mathrm{MIP} 1 \alpha)$ or tumor necrosis factor (TNF $\alpha$ ). However, several studies showed up- or down-regulation of these cytokines. First, Roberson et al. (2012) reported that the levels of GM-CS and MIP1 $\alpha$ were significantly lower in the hippocampi of TS mice. In addition, Zampieri et al. (2014) found that in children with DS, the gene that codifies IL10 was upregulated, while the genes that codified CD40 and IL6 were downregulated. By contrast, increases in the expression of IL6 have been reported in children with DS (Zaki et al., 2017) and in the TS mouse (Hamlett et al., 2018). Finally, in contrast to the lack of changes in the expression of TNF $\alpha$ displayed by the TS mice in our study, increased levels of this cytokine have been found both in children with DS (Zaki et al., 2017) and in TS mice (Hamlett et al., 2018). These discrepancies may be due to different methods or tissues used to quantify these cytokines, the fact that some of the studies were performed in humans with DS, the age of the animals or the experimental manipulations preceding the assessments reported in the different studies.

IL17 plays an important role in inflammatory brain disorders, as demonstrated by the increased levels of this cytokine in multiple sclerosis (Tzartos et al., 2008), infectious CNS diseases (Guiton et al., 2010) and stroke (Shichita et al., 2009; Li et al., 2005). The role of IL17 in mediating brain damage in neuroinflammatory processes has been associated with its ability to induce the expression of other pro-inflammatory chemokines and cytokines (Zimmermann et al., 2013; Meares et al., 2012; Korn et al., 2009). IL17 can work synergistically with IL1 $\beta$ and IFN $\gamma$ to increase the production of other pro-inflammatory mediators (Onishi and Gaffen, 2010). In addition, IL1 $\beta$ and IL15, whose levels are increased in the hippocampi of TS mice, can also induce the expression of IL17 (Sutton et al., 2006; Ferretti et al., 2003) and potentiate its pro-inflammatory effects (Flores-García and TalamásRohana, 2005; Ferretti et al., 2003), suggesting the existence of positive feedback circuits induced by IL17 and other cytokines (Flores-García and Talamás-Rohana, 2005). In this regard, we show herein that the enhanced expression of IFN $\gamma$, IL1 $\beta$, IL15, MIP3 $\alpha$, G-CSF and IL17A observed in the hippocampi of the TS mice is significantly reduced by the chronic administration of an anti-IL17 mAb. 


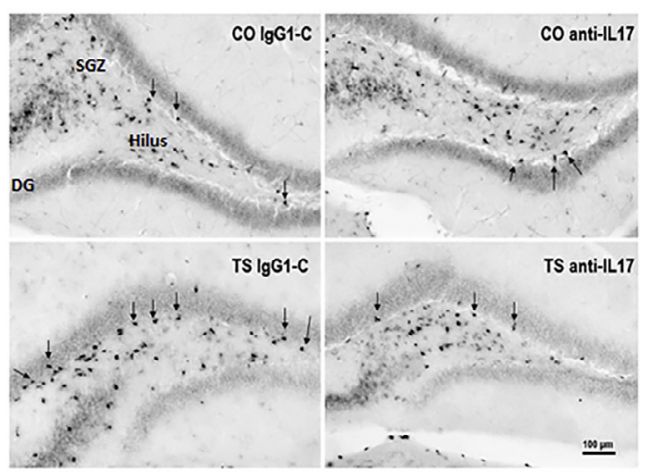

B

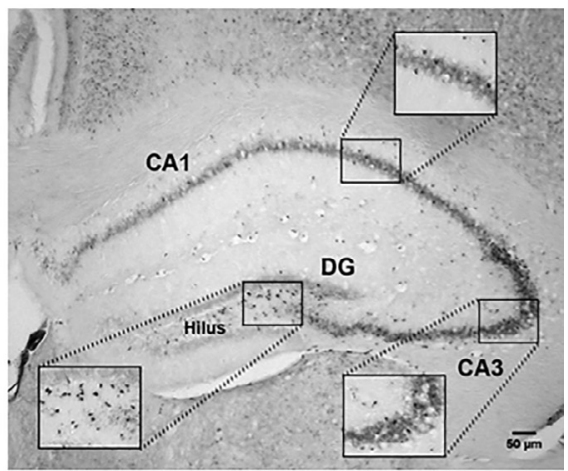

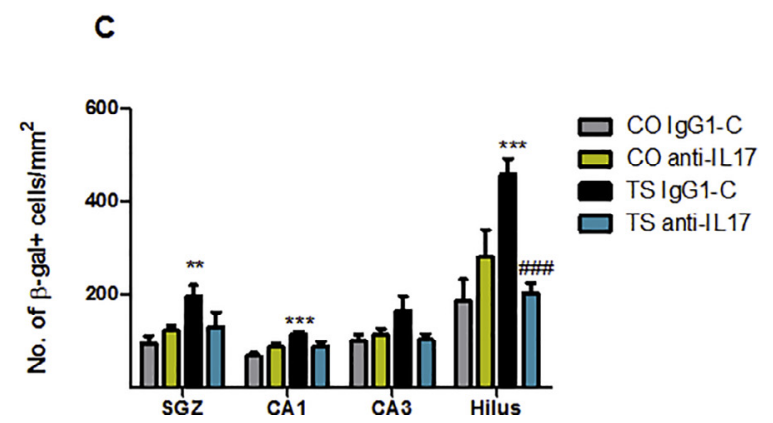

Fig. 7. Representative images of cells with a senescent phenotype in the SGZ and hilus (A) and in the hippocampal CA1, CA3 and hilar regions (B). Mean \pm S.E.M. of the density of $\beta$-galactosidase + cells in the SGZ, CA1, CA3 and hilar regions (C) of TS and CO IgG1-C- and anti-IL-17-treated mice. ${ }^{* * *}: \mathrm{p}<0.01,{ }^{* * * *}: \mathrm{p}<0.001$ TS vs. CO; ${ }^{\# \#}: \mathrm{p}<0.001$ anti-IL17 vs. vehicle. Bonferroni tests after significance by ANOVA.

A

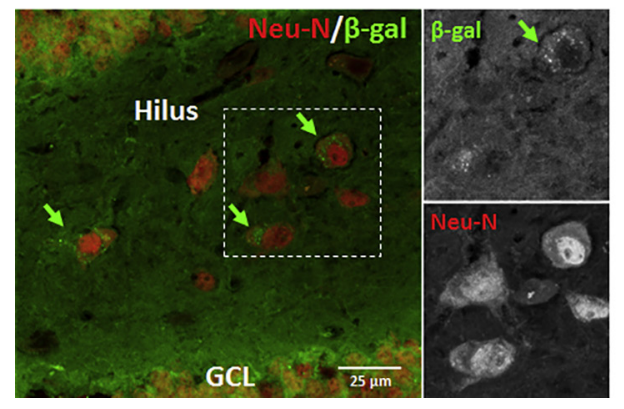

B

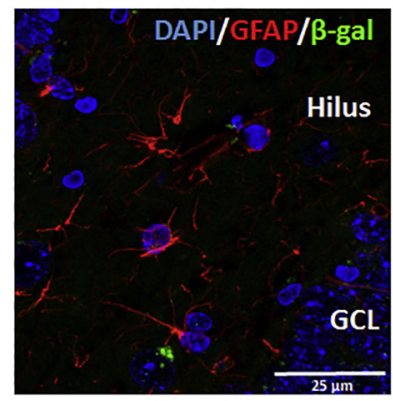

C

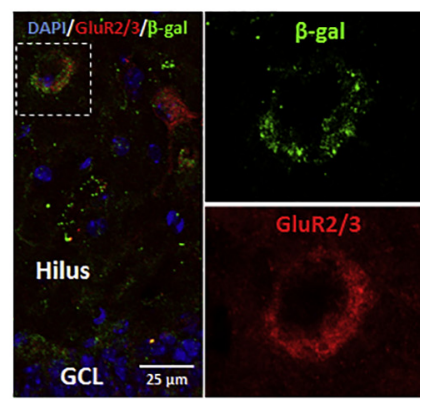

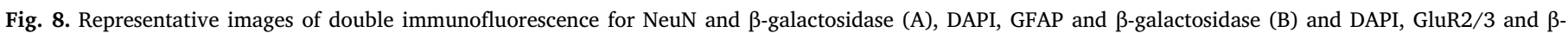
galactosidase (C) in the hilar region of a vehicle-treated TS animal.

Further evidence of increased neuroinflammation in the brains of TS animals comes from studies showing increased activated microglia in the septa and hippocampi of TS mice (Hunter et al., 2004) and from the present results showing an increase in the density of these cells in the cortexes and hippocampi of TS animals. Chronic administration of antiIL17 induced a decrease in activated microglia in both structures since TS animals treated with this antibody did not differ from vehicletreated $\mathrm{CO}$ animals in terms of this measure. These results provide evidence for the neuroprotective effects of the chronic administration of anti-IL17.

Consistent with the cognitive alterations found in $\mathrm{DS}$ and $\mathrm{AD}$ and in the mouse models of these conditions (see Rueda and Martínez-Cué, 2015; Rueda et al., 2012; Bartesaghi et al., 2011), in the present study, aged TS mice displayed profound deficits in their abilities to learn a spatial task. Chronic administration of anti-IL17 ameliorated the spatial learning deficits of TS mice. This treatment also improved the performance of the $\mathrm{CO}$ mice in the same test. This beneficial effect is likely due to an enhancement in the cognitive abilities and not to an improvement in the motor or motivational abilities of the animals since the different groups of mice did not differ in their latency to reach the visible platform during the cued trials or in their swimming speed. Further support for this specific pro-cognitive effect of anti-IL17 administration comes from the finding that the administration of the IgG1-C isotype control did not induce an effect on the performances of the TS or CO animals in the water maze.

Consistent with our results, several studies have demonstrated that blocking this cytokine reduces brain damage associated to neuroinflammatory processes (Korn et al., 2009; Meares et al., 2012; Zimmermann et al., 2013, 2018). IL17 inhibitors have shown beneficial effects in different autoimmune pathologies, such as experimental autoimmune encephalitis and multiple sclerosis (Uyttenhove and Van Snick, 2006; Mardiguian et al., 2013) and multiple sclerosis. In addition, the administration of anti-IL17 antibodies reduces inflammation and improves the neurological outcomes of different CNS pathologies, 


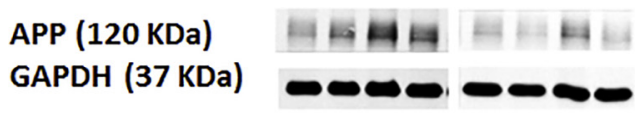

A

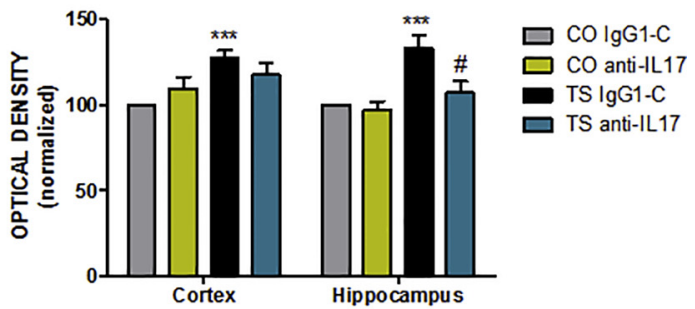

B

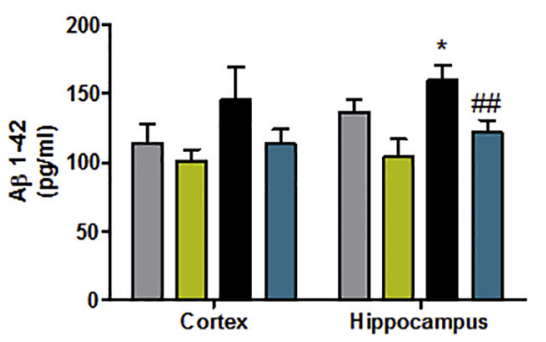

C

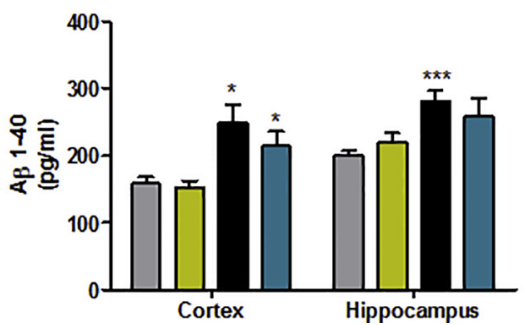

Fig. 9. Western blot analysis of APP levels (differences are expressed relative to the values of the vehicle-treated CO mice, defined as $100 \%$ ) (A), ELISA analysis of the $A \beta_{1-42}(B)$ and $A \beta_{1-40}$ (C) levels in the cortices and hippocampi of the vehicle- and anti-IL17-treated TS and CO mice. ${ }^{*}: \mathrm{p}<0.05,{ }^{* * * *}: \mathrm{p}<0.001$, TS vs. CO; ${ }^{\#}: \mathrm{p}<0.05,{ }^{\# \#}: \mathrm{p}<0.01$, IgG1-C vs. anti-IL17; Bonferroni tests after significance by ANOVA.

such as recovery after stroke, ischemia or encephalic inflammation, in which an important inflammatory component exists (Dallenbach et al., 2015; Swardfager et al., 2013; Flores-García and Talamás-Rohana, 2005; Gelderblom et al., 2012).

Despite this evidence, the role of IL17 in AD pathology remains unclear. In a rat model of $\mathrm{AD}$, the increased expression of IL17 in the hippocampus after Th17 cell infiltration into the brain parenchyma aggravates neuroinflammation and neurodegeneration (Zhang et al., 2013). In addition, in the APP/PS1 mouse model of AD, the infiltration

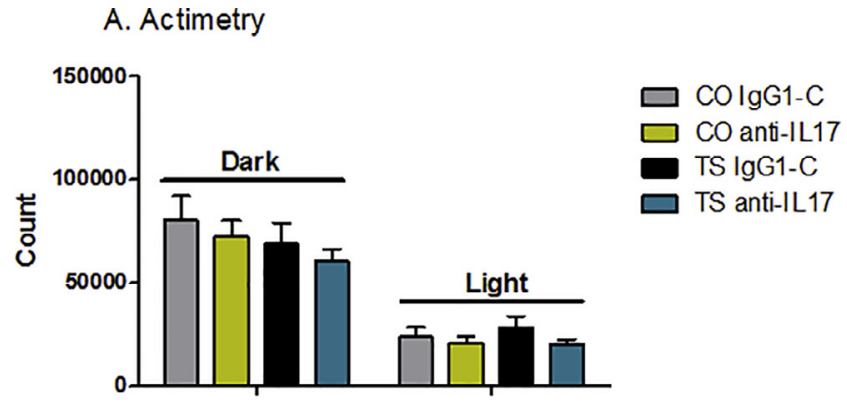

B. Rotarod (constant speeds)

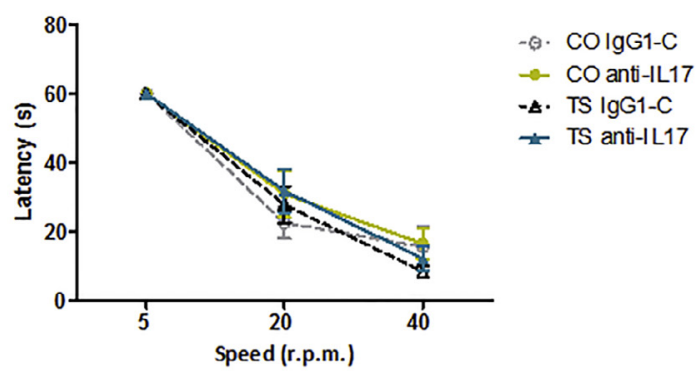

C. Rotarod (acceleration cycle)

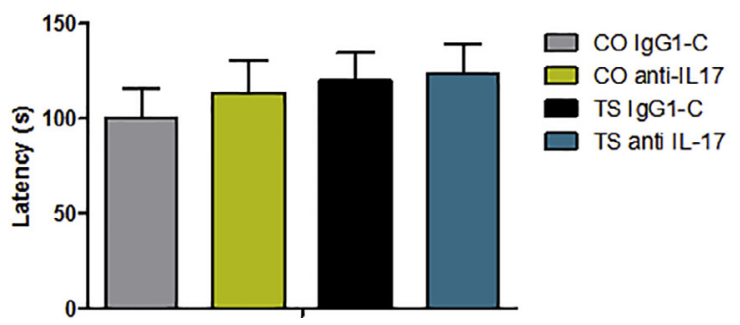

Fig. 10. Mean \pm S.E.M. of the average spontaneous activity of the TS and CO mice treated with IgG1-C or anti-IL-17 during $24 \mathrm{~h}$ of the dark-light cycle (A), of the latency to fall from the rotarod at different constant speeds (B) and during the acceleration cycle (C).

of IL17-producing T cells after infection with a common human pathogen increases glial activation and amyloid- $\beta$ deposition (McManus et al., 2014). Conversely, Yang et al. (2017) have demonstrated that intracranial IL17 overexpression decreases cerebral amyloid angiopathy in another mouse model of AD. The mechanism of action of IL17 in astrocytes, microglia and neurons involves the binding of IL17 to its

Table 3

Score of vehicle- and anti-IL17-treated TS and CO mice in the sensorimotor test battery.

\begin{tabular}{|c|c|c|c|c|c|c|c|c|}
\hline & & \multicolumn{2}{|l|}{ IgG1-C } & \multicolumn{2}{|l|}{ anti- IL17 } & \multicolumn{3}{|l|}{$F_{(1,48)}$} \\
\hline & & $\mathrm{CO}$ & TS & $\mathrm{CO}$ & TS & Genotype & Treatment & Genotype $\mathrm{x}$ treatment \\
\hline \multicolumn{2}{|l|}{ Vision } & $2.41 \pm 0.14$ & $2.30 \pm 0.13$ & $2.58 \pm 0.14$ & $2.42 \pm 0.13$ & $0.86, p=0.35$ & $1.02, \mathrm{p}=0.31$ & $0.02, p=0.87$ \\
\hline \multicolumn{2}{|l|}{ Startle reflex } & $1.00 \pm 0.12$ & $1.53 \pm 0.21^{*}$ & $1.16 \pm 0.11$ & $1.14 \pm 0.36$ & $3.13, p=0.08$ & $0.32, \mathrm{p}=0.43$ & $3.74, p=0.06$ \\
\hline \multicolumn{2}{|c|}{ Righting reflex } & $3.00 \pm 0.00$ & $3.00 \pm 0.00$ & $3.00 \pm 0.00$ & $3.00 \pm 0.00$ & & & \\
\hline \multicolumn{2}{|c|}{ Grip strength } & $2.66 \pm 0.22$ & $2.07 \pm 0.23$ & $2.25 \pm 0.27$ & $2.00 \pm 0.23$ & $2.86, p=0.09$ & $0.86, p=0.35$ & $0.82, p=0.37$ \\
\hline \multirow[t]{2}{*}{ Equilibrium } & Wooden bar & $2.25 \pm 0.17$ & $2.00 \pm 0.00$ & $2.66 \pm 0.25$ & $1.92 \pm 0.07^{*}$ & $10.52 p=0.002$ & $1.28, \mathrm{p}=0.26$ & $2.56, \mathrm{p}=0.11$ \\
\hline & Aluminum bar & $0.33 \pm 0.22$ & $0.23 \pm 0.23$ & $0.25 \pm 0.25$ & $0.14 \pm 0.09$ & $0.26, \mathrm{p}=0.61$ & $0.17, \mathrm{p}=0.67$ & $0.00, p=0.99$ \\
\hline \multicolumn{2}{|c|}{ Latency, wooden bar } & $20.00 \pm 0.00$ & $20.00 \pm 0.00$ & $20.00 \pm 0.00$ & $19.46 \pm 0.53$ & $0.82, \mathrm{p}=0.37$ & $0.82, \mathrm{p}=0.37$ & $0.82, \mathrm{p}=0.37$ \\
\hline \multicolumn{2}{|c|}{ Latency, aluminum bar } & $6.50 \pm 1.08$ & $4.61 \pm 0.81$ & $7.16 \pm 1.94$ & $6.21 \pm 1.44$ & $1.05, \mathrm{p}=0.30$ & $0.67, p=0.41$ & $0.11, p=0.73$ \\
\hline \multicolumn{2}{|c|}{ Prehensile reflex } & $2.66 \pm 0.25$ & $2.23 \pm 0.23$ & $2.66 \pm 0.14$ & $2.42 \pm 0.20$ & $2.50, p=0.12$ & $0.21, p=0.64$ & $0.21, p=0.64$ \\
\hline \multicolumn{2}{|c|}{ Traction capacity } & $1.5 \pm 0.59$ & $1.00 \pm 0.35$ & $1.50 \pm 0.43$ & $1.85 \pm 0.49$ & $0.02 p=0.88$ & $0.80, p=0.37$ & $0.37, p=0.93$ \\
\hline \multirow[t]{3}{*}{ Coat hanger } & Latency to fall & $26.91 \pm 6.43$ & $13.61 \pm 5.15$ & $34.91 \pm 7.16$ & $16.57 \pm 5.96$ & $6.53, p=0.01$ & $0.78, p=0.38$ & $0.16, p=0.68$ \\
\hline & Crossings & $3.83 \pm 0.75$ & $1.69 \pm 0.63^{*}$ & $4.50 \pm 0.92$ & $2.64 \pm 0.76$ & $6.65, p=0.013$ & $1.08, \mathrm{p}=0.30$ & $0.03, p=0.85$ \\
\hline & Latency of arrival & $33.00 \pm 6.28$ & $37.53 \pm 7.62$ & $25.33 \pm 6.23$ & $35.28 \pm 6.76$ & $1.12 p=0.29$ & $0.52, \mathrm{p}=0.47$ & $0.15, p=0.69$ \\
\hline
\end{tabular}




\section{A. Open Field (horizontal activity)}

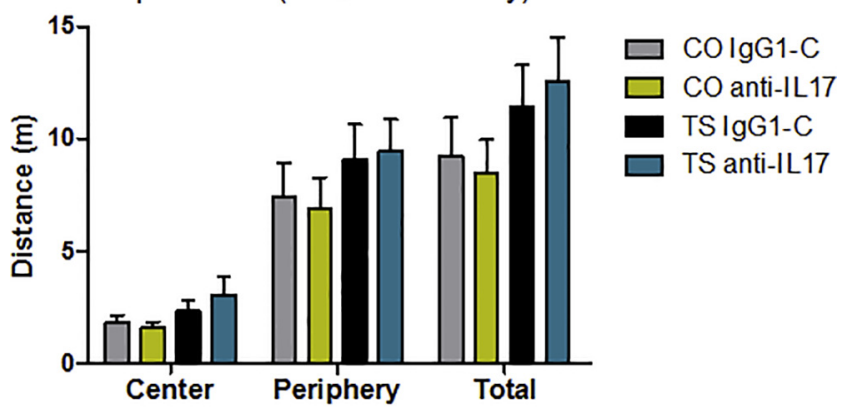

\section{B. Open Field (vertical activity)}

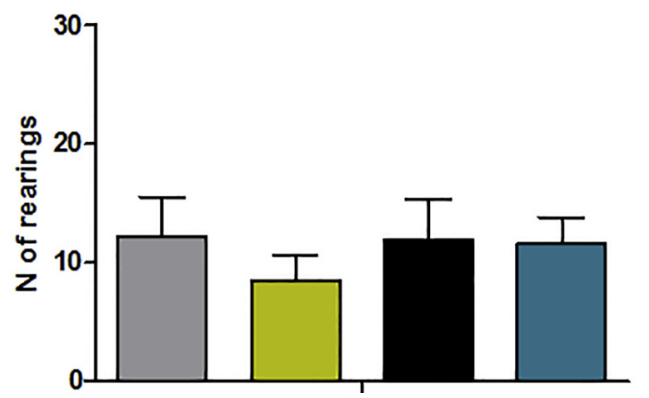

Fig. 11. Mean \pm S.E.M. of the distance traveled in the center and periphery, of the total distance traveled (A) and of the number of rearings performed by the TS and CO mice treated with IgG1-C or anti-IL-17 in the open field test. receptor, which activates inflammatory pathways, thereby inducing the expression of pro-inflammatory genes through a signaling pathway that ends with the activation of the transcription factor NF-k $\beta$. NF-k $\beta$ is implicated in astrocytosis and microglial activation, inducing the expression of other pro-inflammatory cytokines, such as IL6, TNF $\alpha$, and IL1 $\beta$, and several chemokines (Korn et al., 2009).

In the present study, the administration of anti-IL17 to the TS or CO mice did not induce behavioral side effects since the sensorimotor abilities, spontaneous activity, motor coordination and anxiety levels of the animals remained unaffected.

In the plus maze test, no significant differences were found between $\mathrm{CO}$ and TS mice under the different treatments in any component of their behavior in an anxiogenic situation. However, TS mice tended to make more entries and spend more time in the open arms. This result is consistent with the results of previous work from our and other laboratories reporting that TS mice run a longer distance and spent more time in open arms (Cousons-Read and Crnic, 1996; Demas et al., 1996; Escorihuela et al., 1998). However, rather than enhanced anxiety, these behaviors displayed by TS mice have been proposed to be due to reduced attention to potentially dangerous stimuli (Crnic and Pennington, 2000).

Several non-mutually exclusive mechanisms may account for the beneficial effect of the anti-IL17 treatment on the cognitive abilities of TS mice. Increased neuroinflammation in DS brains appears to be mainly mediated by the exacerbation of macrophage activation state 1 (M1) cells due to the triplication of some critical inflammatory-associated genes, including RCAN1, CXADR, ADAMTS1, ADAMTS5, TIAM1, and IFNGR2 (Wilcock and Griffin, 2013; Wilcock, 2012; Martin et al., 2012). M1 macrophages possess potent pro-inflammatory properties, which are characterized by the release of reactive oxygen species (ROS) and several cytokines, mainly comprising IFN $\gamma$ and TNF $\alpha$ but also IL1 $\beta$,

\section{A. Number of entries}

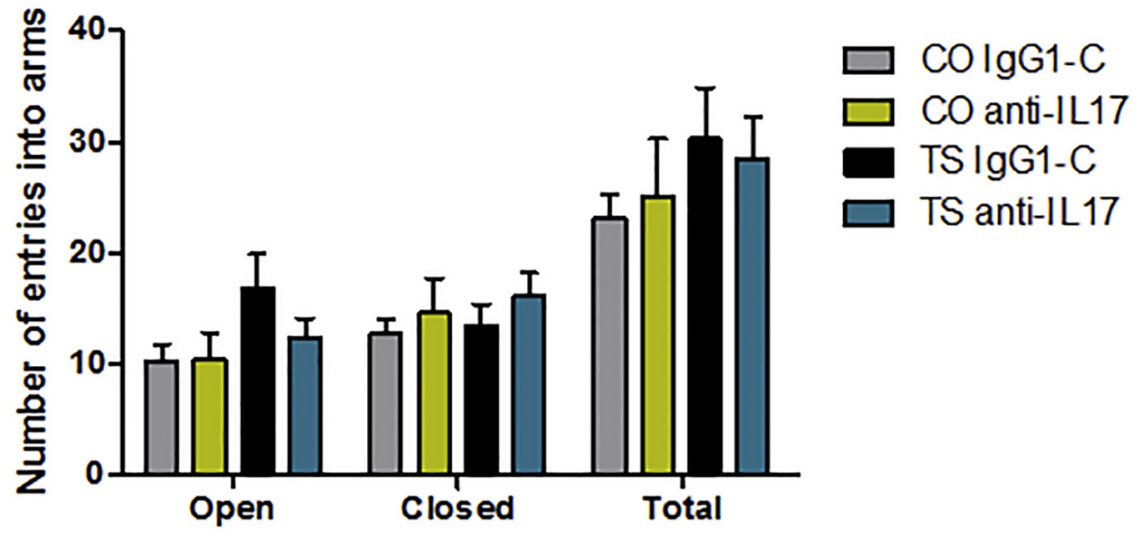

\section{Percentage of time in open arms}

B. Initial freezing time
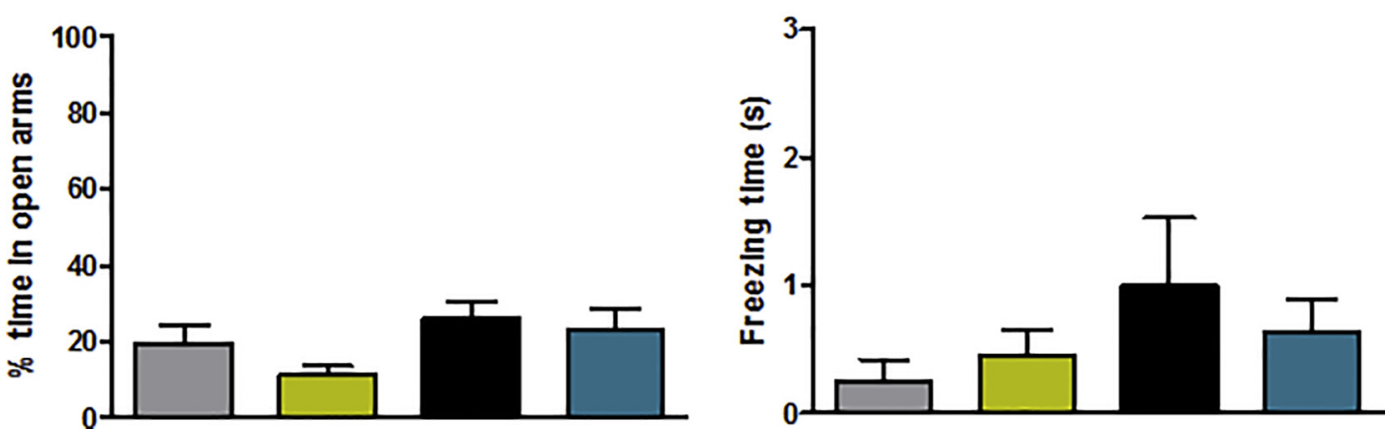

Fig. 12. Mean \pm S.E.M. of the number of entries into the open and closed arms (A), the initial freezing time (B) and the percentage of time spent in the open arms (C) by the TS and CO mice treated with IgG1-C or anti-IL17 in the Plus maze test. 
IL6 and IL12. The expression of several of these M1 mediators (e.g., IL1 $\beta$ and IFN $\gamma$ ) is increased in the hippocampi of TS mice and decreases after anti-IL17 administration. These findings suggest that the inflammatory profile found in the brains of TS mice can be associated with an increased M1 inflammatory response, as occurs in DS brains, and that the anti-IL17 treatment may exert its therapeutic activity by modulating M1 macrophage polarization and/or activity.

Neuroinflammation is one of the most potent inducers of the increased levels of APP and A $\beta$ in AD and DS. An excess of cytokine production, especially of IL1 $\beta$, leads to the overexpression of APP (Liu et al., 2011; Sheng et al., 1996) and accelerated formation of A $\beta$ plaques (Sheng et al., 1997). Furthermore, the high production of other cytokines, such as IFN $\gamma$, may also act in combination with IL1 $\beta$ to increase the production of intracellular $A \beta$ in neurons and astrocytes (Blasko et al., 2001). In addition, in AD, activated astrocytes and microglia are located around amyloid plaques, which suggests that $\mathrm{A} \beta$ activates this inflammatory pathway. Thus, a positive feedback mechanism likely exists between pro-inflammatory cytokine production, the A $\beta$ burden and the APP level (Wilcock and Griffin, 2013). In DS, the overexpression of the triplicated gene APP is accompanied by an increase in IL1 $\beta$ levels and in microglial and astrocytic activation, with increases in APP expression (Wilcock and Griffin, 2013; Sheng et al., 1996; Li et al., 1998). Such glial activation and cytokine overexpression in DS occurs years before the appearance of $\mathrm{A} \beta$ plaques (Wisniewski et al., 1985). Although the TS mouse contains an extra copy of the App gene, these mice do not develop amyloid plaques; however, these mice display increased expression of full-length APP mRNA and protein in the cortex and hippocampus (Corrales et al., 2013; Rueda et al., 2010; Choi et al., 2009; Seo and Isacson, 2005). Consistent with the enhanced App levels found in this study, the present study and numerous studies from other laboratories have demonstrated that the hippocampal and cortical levels of both peptides, namely, $A \beta_{1-40}$ and $A \beta_{1-42}$, are increased in TS mice (Corrales et al., 2013; Netzer et al., 2010). These alterations may contribute to neuronal and cognitive degeneration in these animals because of the role of these peptides in the degeneration of cholinergic neurons. In fact, in normal rodents, cognitive alterations can be induced by intracerebral or intracerebroventricular infusion of $A \beta$ peptides into the brain (for review, see Lawlor and Young, 2010), and in TS mice, chronic treatment with A $\beta$-lowering drugs restores their cognitive abilities (Netzer et al., 2010). Our present results are consistent with roles of inflammatory cytokines, particularly IL17A, in the enhanced expression of APP in the brains of TS mice. Indeed, the reduced expression of pro-inflammatory cytokines after the administration of anti-IL17 normalized the APP levels in the TS mice and the $A \beta_{1-42}$ levels in the hippocampi of both the TS and CO mice. Because of the role of the $A \beta$ load on cognitive deficits and because of the interrelation between $A \beta$, App and pro-inflammatory cytokine production, the enhanced cognitive abilities of the TS mice after anti-IL17 administration might be mediated by the ability of anti-IL17 to reduce these cytokines and normalize APP and A $\beta$ levels. Future studies should determine whether the reduction in APP levels is due to a reduction in transcription or to the increased degradation of the gene product.

However, the cognitive improvement in the anti-IL17-treated TS animals was only partial, suggesting that other altered mechanisms implicated in their memory impairments are not rescued by this treatment.

Another consequence of neuroinflammation is the exacerbation of neurodegeneration, particularly of basal forebrain-cholinergic neurons (BFCN), in AD and DS brains, (Griffin et al., 1989; Wenk et al., 2000; Wilcock and Griffin, 2013). In TS mice, several studies have demonstrated an age-dependent decline in BFCN markers that correlates with cognitive deterioration (Granholm et al., 2000; Hunter et al., 2004; Seo and Isacson, 2005). TNF $\alpha$ produces retrograde degeneration of BFCNs in TS mice. In addition, IL1 $\beta$ induces the synthesis and activity of acetylcholinesterase, thus favoring the breakdown of acetylcholine (Li et al., 2000), which plays a fundamental role in learning and memory
(Levin et al., 1994). Moreover, BFCN degeneration activates inflammatory pathways, and thus, neurodegeneration and neuroinflammation also have interactive and escalating effects in these animals. In the present study, we found that 12-month-old vehicle-treated TS mice showed a reduced density of BFCNs. Treatment with anti-IL17 attenuated this neuronal loss, although the effect was not very pronounced. These results suggest that reducing neuroinflammation is not sufficient to totally prevent cholinergic neurodegeneration in TS animals.

In human astrocytes (Bhat et al., 2012) and mouse neurons (Jurk et al., 2012), cells with a senescent phenotype, a process that is characterized by permanent arrest of cell proliferation (Vidal et al., 2012), may contribute to the dysfunction of the aging brain. Cell senescence is mainly induced by enhanced oxidative stress (Zhou et al., 2015; Rodríguez-Sureda et al., 2015; He et al., 2013). Fibroblasts with trisomy 21 present signs of premature cell senescence that is secondary to increased oxidative damage (Rodríguez-Sureda et al., 2015). Consistent with these findings, we have recently demonstrated that the hippocampus of adult TS mice show greater amounts of oxidative damage and increased densities of cells with a senescent phenotype (Parisotto et al., 2016; García-Cerro et al., 2017). IL17A releases ROS (Huppert et al., 2010), and thus, the blockade of IL17A can reduce oxidative stress, preventing the cells from acquiring a senescent phenotype. In the present study, the anti-IL17 treatment attenuated the increased density of cells with a senescent phenotype in the SGZ, CA1 and CA3 in the hippocampi of TS mice. Although this effect did not reach statistical differences, anti-IL17-treated TS mice presented a similar density of senescent cells in these areas to that of the vehicle-treated CO mice. In addition, this treatment exerted a strong reduction in cellular senescence in the hilar region of TS animals. The analysis of the phenotype of these senescent cells in the hilar region showed that most of them were neurons and that some of them were mossy cells, which have been demonstrated to have an important role in spatial learning (Danielson et al., 2017). Together, these results suggest that the reduction in senescence might have partially played a role in the pro-cognitive effect of the chronic administration of this antibody.

Neuroinflammation also affects adult neurogenesis and has both detrimental and beneficial consequences, which can result in the enhancement and/or inhibition of neurogenesis (see Llorens-Martín et al., 2014). In particular, increased levels of IL1 $\beta$ or IFN $\gamma$, which are elevated in the hippocampi of TS mice, decrease proliferation, survival and neuronal differentiation (Fuster-Matanzo et al., 2013; Villeda et al., 2011). Therefore, the enhanced levels of these pro-inflammatory mediators might also be partially responsible for the altered neurogenesis found in the TS mouse. The reduced expression of IL1 $\beta$ and IFN $\gamma$ after the anti-IL17 treatment correlated with the effect of this antibody on adult neurogenesis because the total number of proliferating (Ki67+) cells was higher in TS mice after anti-IL17 administration. In addition, this treatment exerted a mild beneficial effect on the survival of hippocampal granular cells. The total density and number of cells (DAPI+) and of neurons (NeuN + ) was slightly higher after anti-IL17 administration and did not differ from the number and density found in vehicletreated $\mathrm{CO}$ mice.

The results presented here suggest that IL-17A-mediated neuroinflammation is involved in several AD phenotypes in TS mice and provides a new therapeutic target toward reducing these pathological characteristics. Furthermore, the fact that the treatment with anti-IL17 $\mathrm{mAb}$ ameliorates some of these altered phenotypes in this model of DS offers new perspectives for the therapy of $\mathrm{AD}$ and $\mathrm{DS}$ by using anti-proinflammatory cytokine antibodies. However, many of the putative mechanisms underlying the cognitive abilities of the TS animals were only partially affected by chronic anti-IL17 administration, and the improvements induced by this treatment in terms of the learning and memory deficits of the TS mice were only partial. Therefore, future studies should explore the efficacies of other antibodies targeting other pro-inflammatory cytokines, such as IL1 $\beta$. 


\section{Acknowledgements}

This study was supported by the Jerome Lejeune Foundation, Fundación Tatiana Pérez de Guzmán el Bueno, the Spanish Ministry of Economy and Competitiveness (PSI-2016-76194-R, SAF2014-55088-R, SAF2017-82905-R, SAF2016-75195-R, AEI/FEDER, EU) and Luchamos por la Vida Foundation.

The authors wish to express their gratitude to Dr. Juan M. Hurlé for providing the chicken anti- $\beta$-galactosidase antibody and for his helpful suggestions. The authors also wish to thank Eva García Iglesias for technical assistance and to Victor M. Campa for his help with the analyses of confocal images.

\section{References}

Barger, S.W., Harmon, A.D., 1997. Microglial activation by alzhelmer amyloid precursor protein and modulation by apolipoprotein E. Nature 388, 878-881.

Bartesaghi, R., Guidi, S., Ciani, E., 2011. Is it possible to improve neurodevelopmental abnormalities in Down syndrome? Rev. Neurosci. 22, 419-455.

Beringer, A., Noack, M., Miossec, P., 2016. IL-17 in chronic inflammation: from discovery to targeting. Trends. Mol. Med. 22, 230-241.

Bhat, R., Crowe, E.P., Bitto, A., et al., 2012. Astrocyte senescence as a component of Alzheimer's disease. PLoS One. 7, e45069.

Blasko, I., Ransmayr, G., Veerhuis, R., Eikelenboom, P., Grubeck-Loebenstein, B., 2001 Does IFNg play a role in neurodegeneration? J. Neuroimmunol. 116, 1-4.

Blurton-Jones, M., Laferla, F.M., 2006. Pathways by which Abeta facilitates tau pathology. Curr. Alzheimers Res. 3, 437-448.

Bowes, C., Li, T., Frankel, W.N., Danciger, M., Coffin, J.M., Applebury, M.L., Farber, D.B., 1993. Localization of a retroviral element within the rd gene coding for the beta subunit of cGMP phosphodiesterase. Proc. Natl. Acad. Sci. U.S.A. 90, 2955-2959.

Busciglio, J., Yankner, B.A., 1995. Apoptosis and increased generation of reactive oxygen species in Down's syndrome neurons in vitro. Nature 378, 776-779.

Carta, M.G., Serra, P., Ghiani, A., Manca, E., Hardoy, M.C., Del Giacco, G.S., Diaz, G., Carpiniello, B., Manconi, P.E., 2002. Chemokines and pro-inflammatory cytokines in Down's syndrome: an early marker for Alzheimer-type dementia? Psychother Psychosom 2002 (71), 233-236.

Cenini, G., Dowling, A.L., Beckett, T.L., Barone, E., Mancuso, C., Murphy, M.P., et al., 2012. Association between frontal cortex oxidative damage and beta-amyloid as a function of age in Down syndrome. Biochim. Biophys. Acta. 1822, 130-138.

Chen, G., Chen, K.S., Knox, J., Inglis, J., Bernard, A., Martin, S.J., Justice, A., McConloque, L., Games, D., Freedman, S.B., Morris, R.G., 2000. A learning deficit related to age and beta-amyloid plaques in a mouse model of Alzheimer's disease. Nature 408, 975-979.

Chong, Y., 1997. Effect of a carboxy-terminal fragment of the Alzheimer's amyloid precursor protein on expression of proinflammatory cytokines in rat glial cells. Life Sci. 61, 2323-2333.

Choi, J.H., Berger, J.D., Mazzella, M.J., Morales-Corraliza, J., Cataldo, A.M., Nixon, R.A., et al., 2009. Age-dependent dysregulation of brain amyloid precursor protein in the Ts65Dn Down syndrome mouse model. J. Neurochem. 110, 1818-1827.

Corrales, A., Vidal, R., García, S., Vidal, V., Martínez, P., García, E., et al., 2014. Chronic melatonin treatment rescues electrophysiological and neuromorphological deficits in a mouse model of Down syndrome. J. Pineal. Res. 56, 51-61.

Corrales, A., Martínez, P., García, S., Vidal, V., García, E., Flórez, J., et al., 2013. Long term oral administration of melatonin improves spatial learning and memory and protects against cholinergic degeneration in middle-aged Ts65Dn mice, a model of Down syndrome. J. Pineal. Res. 54, 346-358.

Cousons-Read, M.E., Crnic, L.S., 1996. Behavioral assessment of the Ts65Dn mouse, a model for Down syndrome: altered behavioral in the elevated plus maze and open field. Behav. Genet 26, 7-13.

Crnic, L.S., Pennington, B.F., 2000. Down syndrome: neurophychology and animals models. Prog. Infancy Res. 1, 69-111.

Dallenbach, K., Maurer, P., Röhn, T., Zabel, F., Kopf, M., Bachmann, M.F., 2015. Protective effect of a germline, IL-17-neutralizing antibody in murine models of autoimmune inflammatory disease. Eur. J. Immunol. 45, 1238-1247.

Danielson, N.B., Turi, G.F., Ladow, M., Chavlis, S., Petrantonakis, P.C., Poirazi, P., Losonczy, A., 2017. In vivo imaging of dentate gyrus mossy cells in behaving mice. Neuron 9, 552-559.

Demas, G.E., Nelson, R.J., Krueger, B.K., Yarowsky, P.J., 1996. Spatial memory deficits in segmental trisomic Ts65Dn mice. Behav. Brain Res. 82, 85-92.

Dickson, D.W., Lee, S.C., Mattiace, L.A., Yen, S.H., Brosnan, C., 1993. Microglia and cytokines in neurological disease, with special reference to AIDS and Alzheimer's disease. Glia 7, 75-83.

Eikelenboom, P., Veerhuis, R., Scheper, W., Rozemuller, A.J.M., van Gool, W.A., Hoozemans, J.J.M., 2006. The significance of neuroinflammation in understanding Alzheimer's disease. J. Neural. Transm. 113, 1685-1695.

Escorihuela, R.M., Vallina, I.F., Martinez-Cué, C., Baamonde, C., Dierssen, M., Tobeña, A., Flórez, J., Fernández-Teruel, A., 1998. Impaired short- and long-term memory in Ts65Dn mice, a model for Down syndrome. Neurosci. Lett. 247, 171-174.

Ferretti, S., Bonneau, O., Dubois, G.R., Jones, C.E., Trifilieff, A., 2003. IL- 17, produced by lymphocytes and neutrophils, is necessary for lipopolysaccharide- induced airway neutrophilia: IL-15 as a possible trigger. J. Immunol. 170, 2106-2112.
Flores-García, Y., Talamás-Rohana, P., 2005. Interleucina 17, funciones biológicas y su receptor. REB. 31, 3-9.

Fuster-Matanzo, A., Llorens-Martín, M., Hernández, F., Avila, J., 2013. Role of neuroinflammation in adult neurogenesis and Alzheimer disease: therapeutic approaches. Mediators Inflamm. 2013, 260925.

García-Cerro, S., Rueda, N., Vidal, V., Lantigua, S., Martínez-Cué, C., 2017 Oct Oct. Normalizing the gene dosage of Dyrk1A in a mouse model of Down syndrome rescues several Alzheimer's disease phenotypes. 0.1016/j.nbd.2017.06.010Epub 2017 Jun 21. Neurobiol. Dis. 106, 76-88.

Gelderblom, M., Weymar, A., Bernreuther, C., Velden, J., Arunachalam, P., Steinbach, K., Orthey, E., Arumugam, T.V., Leypoldt, F., Simova, O., Thom, V., Friese, M.A., Prinz, I., Hölscher, C., Glatzel, M., Korn, T., Gerloff, C., Tolosa, E., Magnus, T., 2012. Neutralization of the IL-17 axis diminishes neutrophil invasion and protects from ischemic stroke. Blood 120, 3793-3802.

Gitter, B.D., Cox, L.M., Rydel, R.E., May, P.C., 1995. Amyloid beta peptide potentiates cytokine secretion by interleukin-1 beta-activated human astrocytoma cells. Proc. Natl. Acad. Sci. U.S.A. 92, 10738-10741.

Granholm, A.C., Sanders, L.A., Crnic, L.S., 2000. Loss of cholinergic phenotype in basal forebrain coincides with cognitive decline in a mouse model of Down's syndrome. Exp. Neurol. 161, 647-663.

Griffin, W.S., 2006. Inflammation and neurodegenerative diseases. Am. J. Clin. Nutr. 83, 470S-474S.

Griffin, W.S., Stanley, L.C., Ling, C., White, L., MacLeod, V., Perrot, L.J., et al., 1989. Brain interleukin 1 and S-100 immunoreactivity are elevated in Down syndrome and Alzheimer disease. Proc. Natl. Acad. Sci. U.S.A. 86, 7611-7615.

Guerreiro, R., Bras, J., Hardy, J., 2013. Snapshot: genetics of Alzheimer's disease. Cell 155 968-e961.

Guiton, R., Vasseur, V., Charron, S., Arias, M.T., Van Langendonck, N., et al., 2010. Interleukin 17 receptor signaling is deleterious during toxoplasma gondii infection in susceptible BL6 mice. J. Infect. Dis. 202, 427-435.

Hamlett, E.D., Ledreux, A., Potter, H., Chial, H.J., Patterson, D., Espinosa, J.M., Bettcher, B.M., Granholm, A.C., 2018. Exosomal biomarkers in Down syndrome and Alzheimer's disease. Free Radical Biol. Medicine. 114, 110-121.

Hardy, J., 2006. Has the amyloid cascade hypothesis for Alzheimer's disease been proved? Curr. Alzheimers Res. 3, 71-73.

Hardy, J.A., Higgins, G.A., 1992. Alzheimer's disease: the amyloid cascade hypothesis. Science 256, 184-185.

Haydar, T.F., Reeves, R.H., 2012. Trisomy 21 and early brain development. Trends Neurosci. 35 (2), 81-91.

He, N., Jin, W.L., Lok, K.H., et al., 2013. Amyloid-B(1-42) oligomer accelerates senescence in adult hippocampal neural stem/progenitor cells via formylpeptide receptor 2. Cell Death Dis. 4, e924.

Ho, G.J., Drego, R., Hakimian, E., Masliah, E., 2005. Mechanisms of cell signaling and inflammation in Alzheimer's disease. Curr. Drug Targets. 4, 247-256.

Hunter, C.L., Bachman, D., Granholm, A.C., 2004. Minocycline prevents cholinergic loss in a mouse model of Down's syndrome. Ann. Neurol. 56, 675-688.

Huppert, J., Closhen, D., Croxford, A., White, R., Kulig, P., et al., 2010. Cellular mechanisms of IL-17-induced blood-brain barrier disruption. FASEB J. 24, 1023-1034.

Jurk, D., Wang, C., Miwa, S., et al., 2012. Postmitotic neurons develop a p21-dependent senescence-like phenotype driven by a DNA damage response. Aging Cell. 11, 996-1004.

Korn, T., Bettelli, E., Oukka, M., Kuchroo, V.K., 2009. IL-17 and Th17 cells. Annu. Rev. Immunol. 27, 485-517.

Lawlor, P., Young, D., 2010. Ab infusion and related models of Alzheimer dementia. In: De Deyn, P., Van Dam, D. (Eds.), Animal Models of Dementia. Springer Science and Business Media, New York, pp. 347-370.

Levin, E.D., Briggs, S.J., Christopher, N.C., Auman, J.T., 1994. Working memory performance and cholinergic effects in the ventral tegmental area and substantia nigra. Brain Res. 657, 165-170.

Li, G.-Z., Zhong, D., Yang, L.-M., Sun, B., Zhong, Z.-H., et al., 2005. Expression of interleukin-17 in ischemic brain tissue. Scand. J. Immunol. 62, 481-486.

Li, Y., Liu, L., Kang, J., Sheng, J.G., Barger, S.W., Mrak, R.E., Griffin, W.S., 2000 Neuronal-glial interactions mediated by interleukin-1 enhance neuronal acetylcholinesterase activity and mRNA expression. J. Neurosci. 20, 149-155.

Li, Y., Wang, J., Sheng, J.G., Liu, L., Barger, S.W., Jones, R.A., Van Eldik, L.J., Mrak, R.E., Griffin, W.S., 1998. S100 beta increases levels of beta-amyloid precursor protein and its encoding mRNA in rat neuronal cultures. J. Neurochem. 71, 1421-1428.

Liu, L., Aboud, O., Jones, R.A., Mrak, R.E., Griffin, W.S., Barger, S.W., 2011. Apolipoprotein E expression is elevated by interleukin 1 and other interleukin 1 induced factors. J. Neuroinflammation. 8, 175.

Liu, D.P., Schmidt, C., Billings, T., Davisson, M.T., 2003. A quantitative PCR genotyping assay for the Ts65Dn mouse model of Down syndrome. Biotechniques 35, 1170-1174.

Llorens-Martín, M., Jurado-Arjona, J., Fuster-Matanzo, A., Hernández, F., Rábano, A., Ávila, J., 2014. Peripherally triggered and GSK-3B driven brain inflammation differentially skew adult hippocampal neurogenesis, behavioral pattern separation and microglial activation in response to ibuprofen. Trans. Psychiatry. 4, e463.

Llorens-Martín, M.V., Torres-Alemán, I., Trejo, J.L., 2006. Pronounced individual variation in the response to the stimulatory action of exercise on immature hippocampal neurons. Hippocampus 16, 480-490.

Lockrow, J., Boger, H., Bimonte-Nelson, H., Granholm, A.C., 2011. Effects of long-term memantine on memory and neuropathology in Ts65Dn mice, a model for Down syndrome. Behav. Brain Res. 221, 610-622.

Lockrow, J., Prakasam, A., Huang, P., Bimonte-Nelson, H., Sambamurti, K., Granholm, A.C., 2009. Cholinergic degeneration and memory loss delayed by vitamin $\mathrm{E}$ in a Down syndrome mouse model. Exp. Neurol. 216, 278-289. 
Lott, I.T., 2012. Neurological phenotypes for Down syndrome across the life span. Prog. Brain Res. 197, 101-121.

Lott, I.T., Dierssen, M., 2010. Cognitive deficits and associated neurological complications in individuals with Down's syndrome. Lancet. Neurol. 9 (6), 623-633.

Lowry, O.H., Rosenbrough, N.J., Farr, A.L., Randall, R.J., 1951. Protein measurement with the Folin phenol reagent. J. Biol. Chem. 193, 265-275.

Lyman, M., Lloyd, D.G., Ji, X., Vizcaychipi, M.P., Ma, D., 2014. Neuroinflammation: the role and consequences. Neurosci. Res. 79, 1-12.

Mardiguian, S., Serres, S., Ladds, E., Campbell, S.J., Wilainam, P., McFadyen, C., McAteer, M., Choudhury, R.P., Smith, P., Saunders, F., Watt, G., Sibson, N.R., Anthony, D.C., 2013. Anti-IL-17A treatment reduces clinical score and VCAM-1 expression detected by in vivo magnetic resonance imaging in chronic relapsing EAE ABH mice. Am. J. Pathol. 182, 2071-2081.

Martin, K.R., Corlett, A., Dubach, D., Mustafa, T., Coleman, H.A., Parkington, H.C., et al., 2012. Over-expression of RCAN1 causes Down syndrome-like hippocampal deficits that alter learning and memory. Hum. Mol. Genet. 21, 3025-3041.

Martínez-Cué, C., Martínez, P., Rueda, N., Vidal, R., García, S., Vidal, V., Corrales, A., Montero, J.A., Pazos, A., Flórez, J., Gasser, R., Thomas, A.W., Honer, M., Knoflach, F., Trejo, J.L., Wettstein, J.G., Hernandez, M.C., 2013. Reducing GABAA $\alpha 5$ receptormediated inhibition rescues functional and neuromorphological deficits in a mouse model of Down syndrome. J. Neurosci. 33, 3953-3966.

McManus, R.M., Higgins, S.C., Mills, K.H., Lynch, M.A., 2014. Respiratory infection promotes T cell infiltration and amyloid- $\beta$ deposition in APP/PS1 mice. Neurobiol. Aging. 35, 109-121.

Meager A. Cytokines: interleukins. In Encyclopedia of Molecular Cell Biology and Molecular Medecine, R. Meyers, Ed. 2004. pp. 115-151. Wilhey-VCH,Weinheim, Germany.

Meager A. Viral inhibitors and immune response mediators: the interferons. Iin Encyclopedia of Molecular Cell Biology and Molecular Medecine. R. Meyers, Ed. 2005. pp. 387-421, Wilhey-VCH, Weinheim, Germany.

Meares, G.P., Ma, X., Qin, H., Benveniste, E.N., 2012. Regulation of CCL20 expression in astrocytes by IL-6 and IL-17. Glia. 60, 771-781.

Millan Sanchez, M., Heyn, S.N., Das, D., Moghadam, S., Martin, K.J., Salehi, A., 2012. Neurobiological elements of cognitive dysfunction in down syndrome: exploring the role of APP. Biol. Psychiatry. 71, 403-409.

Murugaiyan, G., Pires da Cunha, A., Akay, A.K., Joller, N., Garo, L.P., Kumaradevan, S., Yosef, N., Vaidya, V.S., Weiner, H.S., 2015. MicroRNA-21 promotes Th17 differentiation and mediates experimental autoimmune encephaolmyelitis. J. Clin. Invest. 126, 1069-1080.

Mulet, M., Blasco-Ibáńez, J.M., Crespo, C., Nácher, J., Varea, E., 2017. Early increased density of cyclooxygenase-2 (COX-2) immunoreactive neurons in Down syndrome. Folia Neuropathol. 55, 154-160.

Netzer, W.J., Powell, C., Nong, Y., Blundell, J., Wong, L., Duff, K., et al., 2010. Lowering beta-amyloid levels rescues learning and memory in a Down syndrome mouse model. PLoS One. 5, e10943.

Onishi, R.M., Gaffen, S.L., 2010. Interleukin-17 and its target genes: mechanisms of interleukin-17 function in disease. Immunology 129, 311-321.

Parisotto, E.B., Vidal, V., García-Cerro, S., Lantigua, S., Wilhelm Filho, D., SanchezBarceló, E.J., Martínez-Cué, C., Rueda, N., 2016. Chronic melatonin administration reduced oxidative damage and cellular senescence in the hippocampus of a mouse model of down syndrome. Neurochem. Res. 41, 2904-2913.

Park, J.I., Strock, C.J., Ball, D.W., Nelkin, B.D., 2005. Interleukin-1beta can mediate growth arrest and differentiation via the leukemia inhibitory factor/JAK/ STAT pathway in medullary thyroid carcinoma cells. Cytokine 29, 125-134.

Roberson, R., Kuddo, T., Horowitz, K., Caballero, M., Spong, C.Y., 2012. Cytokine and chemokine alterations in Down syndrome. Am. J. Perinatol. 29, 705-708.

Rodríguez-Sureda, V., Vilches, Á., Sánchez, O., et al., 2015. Intracellular oxidant activity, antioxidant enzyme defense system, and cell senescence in fibroblasts with trisomy 21. Oxid. Med. Cell Longev. 2015, 509241.

Rosi, S., Belarbi, K., Ferguson, R.A., Fishman, K., Obenaus, A., Raber, J., et al., 2012 Traum ainduced alterations in cognition and Arc expression are reduced by previous exposure to 56Fe irradiation. Hippocampus. 22, 544-554.

Rueda N, Martínez-Cué C. Mouse models of Down syndrome and Alzheimeŕs disease: Similarities and differences. In: A Salehi, M Rafii, C Phillips (Eds). Recent Advances in Alzheimer Research. 2015; 1: 191-250. Bentham Books.

Rueda, N., Flórez, J., Martínez-Cué, C., 2012. Mouse models of Down syndrome as a tool to unravel the causes of mental disabilities. Neural. Plast. 2012, 584071.

Rueda, N., Llorens-Martín, M., Flórez, J., Valdizán, E., Banerjee, P., Trejo, J.L., et al., 2010. Memantine normalizes several phenotypic features in the Ts65Dn mouse model of Down syndrome. J. Alzheimers Dis. 21, 277-290.

Saab, B.J., Saab, A.M.P., Roder, J.C., 2011. Statistical and theoretical considerations for the platform re-location water maze. J Neurosci Methods. 198, 44-52.

Sabbagh, M.N., Fleisher, A., Chen, K., Rogers, J., Berk, C., Reiman, E., et al., 2011. Positron emission tomography and neuropathologic estimates of fibrillar amyloid- $\beta$ in a patient with Down syndrome and Alzheimer disease. Arch Neurol. 68, 1461-1466.

Sastre, M., Dewachter, I., Landreth, G.E., Willson, T.M., Klockgether, T., van Leuven, F., et al., 2003. Nonsteroidal anti-inflammatory drugs and peroxisome proliferator-activated receptor-gamma agonists modulate immunostimulated processing of amyloid precursor protein through regulation of beta-secretase. J Neurosci. 23, 9796-9804.

Seo, H., Isacson, O., 2005. Abnormal APP, cholinergic and cognitive function in Ts65Dn Down's model mice. Exp Neurol. 193, 469-480.

Sheng, J.G., Mrak, R.E., Griffin, W.S., 1997. Neuritic plaque evolution in Alzheimer's disease is accompanied by transition of activated microglia from primed to enlarged to phagocytic forms. Acta Neuropathol. (Berl) 94, 1-5.

Sheng, J.G., Ito, K., Skinner, R.D., Mrak, R.E., Rovnaghi, C.R., Van Eldik, L.J., Griffin,
W.S., 1996. In vivo and in vitro evidence supporting a role for the inflammatory cytokine interleukin-1 as a driving force in Alzheimer pathogenesis. Neurobiol. Aging. 17, 761-766.

Shichita, T., Sugiyama, Y., Ooboshi, H., Sugimori, H., Nakagawa, R., et al., 2009. Pivotal role of cerebral interleukin-17-producing [gamma] [delta] T cells in the delayed phase of ischemic brain injury. Nat. Med. 15, 946-950.

Steele, R.J., Morris, R.G., 1999. Delay-dependent impairment of a matching-to-place task with chronic intrahippocampal infusion of the NMDA-antagonist D-AP5. Hippocampus. 9, 118-136.

Sutton, C., Brereton, C., Keogh, B., Mills, K.H., Lavelle, E.C., 2006. A crucial role for interleukin (IL)- 1 in the induction of IL-17-producing T cells that mediate autoimmune encephalomyelitis. J. Exp. Med. 203, 1685-1691.

Shichiri, M., Yoshida, Y., Ishida, N., Hagihara, Y., Iwahashi, H., Tamai, H., et al., 2011. $\alpha$ Tocopherol suppresses lipid peroxidation and behavioral and cognitive impairments in the Ts65Dn mouse model of Down syndrome. Free Radic. Biol. Med. 50, 1801-1811.

Shin, M., Besser, L.M., Kucik, J.E., Lu, C., Siffel, C., Correa, A., et al., 2009. Prevalence of Down syndrome among children and adolescents in 10 regions of the United States. Pediatrics 124 (6), 1565-1571.

Sipos, E., Kurunczi, A., Kasza, A., Horváth, J., Felszeghy, K., Laroche, S., et al., 2007. Betaamyloid pathology in the entorhinal cortex of rats induces memory deficits: implications for Alzheimer's disease. Neuroscience 147 (1), 28-36.

St-Amour, I., Paré, I., Alata, W., Coulombe, K., Ringuette-Goulet, C., Drouin-Ouellet, J., Vandal, M., Soulet, D., Bazin, R., Calon, F., 2013. Brain bioavailability of human intravenous immunoglobulin and its transport through the murine blood-brain barrier. J. Cereb. Blood Flow Metab. 33, 1983-1992.

Steele, M., Stuchbury, G., Münch, G., 2007. The molecular basis of the prevention of Alzheimer's disease through healthy nutrition. Exp. Gerontol. 42, 28-36.

Sturgeon, X., Gardiner, K.J., 2011. Transcript catalogs of human chromosome 21 and orthologous chimpanzee and mouse regions. Mamm. Genome. 22, 261-271.

Swardfager, W., Winer, D.A., Herrmann, N., Winer, S., Lanctôt, K.L., 2013. Interleukin-17 in post-stroke neurodegeneration. Neurosci. Biobehav. Rev. 37, 436-447.

Tanzi, R.E., Gusella, J.F., Watkins, P.C., Bruns, G.A., St George-Hyslop, P., Van Keuren, M.L., Patterson, D., Pagan, S., Kurnit, D.M., Neve, R.L., 1987. Amyloid beta protein gene: cDNA, mRNA distribution, and genetic linkage near the Alzheimer locus. Science 235, 880-884.

Teipel, S.J., Hampel, H., 2006. Neuroanatomy of Down syndrome in vivo: a model of preclinical Alzheimer's disease. Behav. Genet. 36, 405-415.

Town, T., Nikolic, V., Tan, J., 2005. The microglial "activation" continuum: from innate to adaptive responses. J. Neuroinflammation. 2, 24.

Trazzi Fuchs, C., Valli, E., Perini, G., Bartesaghi, R., Ciani, E., 2013. The amyloid precursor protein (APP) triplicated gene impairs neuronal precursor differentiation and neurite development through two different domains in the Ts65Dn mouse model for Down syndrome. J. Biol. Chem. 288, 20817-20829.

Tzartos, J.S., Friese, M.A., Craner, M.J., Palace, J., Newcombe, J., et al., 2008. Interleukin-17 Production in Central Nervous System-Infiltrating T Cells and Glial Cells Is Associated with Active Disease in Multiple Sclerosis. Am J Pathol. 172, $146-155$.

Uyttenhove, C., Van Snick, J., 2006. Development of an anti-IL-17A auto-vaccine that prevents experimental auto-immune encephalomyelitis. Eur. J. Immunol. 36, 2868-2874.

Vidal, M.A., Walker, N.J., Napoli, E., et al., 2012. Evaluation of senescence in mesenchymal stem cells isolated from equine bone marrow, adipose tissue, and umbilical cord tissue. Stem. Cells Dev. 21, 273-283.

Villeda, S.A., Luo, J., Mosher, K.I., et al., 2011. The ageing systemic milieu negatively regulates neurogenesis and cognitive function. Nature 477, 90-94.

Weldon, D.T., Rogers, S.D., Ghilardi, J.R., Finke, M.P., Cleary, J.P., O'Hare, E., et al., 1998. Fibrillar beta-amyloid induces microglial phagocytosis, expression of inducible nitric oxide synthase, and loss of a select population of neurons in the rat CNS in vivo. J. Neurosci. 18, 2161-2173.

Wenk, G.L., McGann, K., Mencarelli, A., Hauss-Wegrzyniak, B., Del Soldato, P., Fiorucci, S., 2000. Mechanisms to prevent the toxicity of chronic neuroinflammation on forebrain cholinergic neurons. Eur. J. Pharmacol. 402, 77-85.

Wilcock DM. Neuroinflammation in the aging down syndrome brain; Lessons from Alzheimer's disease. Curr Gerontol Geriatr Res. 2012; 1-10.

Wilcock, D.M., Griffin, W.S., 2013. Down's syndrome, neuroinflammation, and Alzheimer neuropathogenesis. J. Neuroinflammation. 10, 84.

Wisniewski, K.E., Dalton, A.J., McLachlan, C., Wen, G.Y., Wisniewski, H.M., 1985. Alzheimer's disease in Down's syndrome: clinicopathologic studies. Neurology 35, 957-961.

Wu, H.P., Shih, C.C., Chu, C.M., Huang, C.Y., Hua, C.C., Liu, Y.C., Chuang, D.Y., 2015. Effect of interleukin-17 on in vitro cytokine production in healthy controls and patients with severe sepsis. J. Formos Med. Assoc. S0929-6646 (14), 00321.

Yang, J., Kou, J., Lalonde, R., Fukuchi, K.I., 2017. Intracranial IL-17A overexpression decreases cerebral amyloid angiopathy by upregulation of ABCA1 in an animal model of Alzheimer's disease. Brain Behav. Immun. 65, 262-273.

Zaki, M.E., El-Bassyouni, H.T., Tosson, A.M., Youness, E., Hussein, J., 2017. Coenzyme Q10 and pro-inflammatory markers in children with Down syndrome: clinical and biochemical aspects. J. Pediatr. (Rio J) 93, 100-104.

Zampieri, B.L., Biselli-Périco, J.M., de Souza, J.E., Bürger, M.C., Silva Júnior, W.A., Goloni-Bertollo, E.M., Pavarino, E.C., 2014. Altered expression of immune-related genes in children with Down syndrome. PLoS One. 9 (9), e107218.

Zimmermann, J., Krauthausen, M., Hofer, M.J., Heneka, M.T., Campbell, I.L., Müller, M., 2013. CNS-Targeted Production of IL-17A Induces Glial Activation, Microvascular Pathology and Enhances the Neuroinflammatory Response to Systemic Endotoxemia. PlosOne. e57307. 
Zimmermann, J., Emrich, M., Krauthausen, M., Saxe, S., Nitsch, L., Heneka, M.T., 2018. Campbell lL, Mülle M. IL-17A promotes granulocyte infiltration, myelin loss, microglia activation, and behavioral deficits during cuprizone-induced demyelination. Mol. Neurobiol. 55, 946-957.

Zhang, J., Ke, K.F., Liu, Z., Qiu, Y.H., Peng, Y.P., 2013. Th17 cell-mediated neuroin-

flammation is involved in neurodegeneration of aß1-42-induced Alzheimer's disease model rats. PLoS One. 4;8 (10), e75786.

Zhou, L., Chen, X., Liu, T., et al., 2015. Melatonin reverses H2 O2 -induced premature senescence in mesenchymal stem cells via the SIRT1-dependent pathway. J. Pineal Res. 59, 190-205.

Zuercher, A.W., Spirig, R., Baz Morelli, A., Käsermann, F., 2016. IVIG in autoimmune disease - Potential next generation biologics. Autoimmun. Rev. 8, 781-785. 